
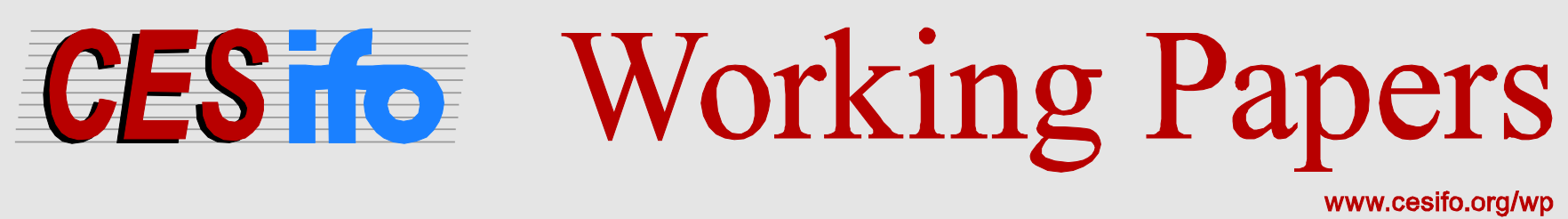

\title{
Central Banking and Financial Stability in the Long Run
}

\author{
Jin Cao \\ Lorán Chollete
}

\author{
CESIFO WORKING PAPER NO. 4272 \\ CATEgory 7: MONETARy POLICY AND INTERNATIONAL FinANCE \\ JUNE 2013
}

Presented at CESifo Area Conference on Macro, Money \& International Finance, February 2013

An electronic version of the paper may be downloaded
- from the SSRN website: $\quad$ www.SSRN.com
- from the RePEc website:
- from the CESifo website: 


\title{
Central Banking and Financial Stability in the Long Run
}

\begin{abstract}
Most theoretical central bank models use short horizons and focus on a single tradeoff. However, in reality central banks play complex, long horizon games and face more than one tradeoff. We account for these issues in a simple infinite horizon game with a novel tradeoff: higher rates deter financial imbalances, but lower rates reduce the likelihood of bankruptcy. We term these factors discipline and stability effects, respectively. The central bank's welfare decreases with dependence between real and financial shocks, so it may reduce costs with correlation-indexed securities. Generally, independent central banks cannot attain both low inflation and financial stability.
\end{abstract}

JEL-Code: E500, G210, G280.

Keywords: central bank, correlation-indexed security, discipline effect, stability effect.

\author{
Jin Cao \\ Norges Bank \\ Bankplassen 2, PB 1179 Sentrum \\ Norway - 0107 Oslo \\ jin.cao@norges-bank.no
}

\author{
Lorán Chollete \\ UiS Business School \\ H142 Ellen og Axel Lunds Hus \\ Norway-4036 Stavanger \\ loran.g.chollete@uis.no
}

June 12, 2013

We are grateful for comments from seminar participants at DIW Berlin, University of Munich, and CESifo Area Conference on Macro, Money \& International Finance. Views expressed in the paper are those of the authors and should not be attributed to Norges Bank. 


\section{Introduction}

What does a central bank do if it finds itself in a situation that was ex ante suboptimal for the banking system? There is a growing literature on optimal central bank policy towards banking intermediaries. Most of this literature uses 3 or 4 period examples of the tension between central bank and intermediary incentives, which often allows for attractive optimality results. ${ }^{1}$ We extend these existing results to account for the fact that, in reality, central banks face long run problems and may have to deal with unexpected situations.

In this paper, we begin to build a simple foundation for central banking policy towards financial fragility over the long run, which we model as an infinitely repeated game. In order to rule out non-credible threats and promises from the central bank, intermediaries and investors, we utilize the criterion of subgame perfection. This condition provides an equilibrium discipline for a central bank that ends up in a crisis state.

\subsection{Overview of the Paper}

Since we cover a lot of ground in this paper, we now present a brief overview to guide the reader. To fix ideas, in Section 2 we present a general form of the fragility-investment tradeoff, in which banks' investment decisions affect the likelihood of systemic events. This negative externality is not internalized by individual banks, and the resulting excessive aggregate investment in the banking sector increases systemic risk.

We further develop this idea in Section 3 by modeling excessive systemic risk-taking arising from a fire sale externality, building on Kashyap and Stein (2012). We proceed in two steps. First, we describe the basic setup, where banks are financing long term projects with a mixture of short and long term debt. While short term debt is cheaper, banks are exposed to liquidity risks when they need to roll over the debt. If creditors refuse to roll over the debts in intermediate term, there will be bank failure and banks have to engage in fire sales, thereby liquidating the premature projects. This fire sale cost increases with the total assets on sale in the market, but individual banks do not internalize such costs when they make their initial investment decisions, thereby leading to excessive investment. The market equilibrium thus features excessive financial fragility and inefficiently high social welfare costs from fire sales. Second, we summarize the central bank's tradeoff between financial

\footnotetext{
${ }^{1}$ See Freixas et al. (2000); chapter 7 of Allen and Gale (2007); and Allen et al. (2009).
} 
fragility, output, and price stability. We formalize this scenario with a production sector and banking sector that experience exogenous output shocks and liquidity shocks, respectively, where these two shocks are potentially correlated. A social welfare maximizing central bank therefore faces dual tradeoffs between financial fragility and inflation, when setting short term rates to stabilize output. The covariance of real and financial shocks reflects a feedback effect that directly affects the central bank's expected loss. In Section 3, this feedback effect is taken as exogenous.

In Section 4 we present an extended model, where we explicitly model feedback between the real economy and banking sector, accounting for banks' strategic response to monetary policy. We proceed in three steps. First, we present the basic framework, with banks that invest in firms' capital via short and long term debt as before. In this framework, an intermediate output shock to real economy affects bank returns, making debt refinancing feasible. When the central bank sets short term interest rates to cushion an output shock, it affects both output and financial fragility. Second, the changing output level implies a change in banks' profit level, affecting their feasibility to refinance. Moreover, the short term interest rate set by the central bank changes banks' refinancing costs, which in turn changes the probability of bank failure. When there are more bank failures, more firms need to be liquidated, thus generating a loss in aggregate output. The key insight from Section 4 is that this feedback effect presents the central bank with a huge dilemma: when the policy rate needs to be raised due to an overheated economy, the central bank cannot raise the rate too high because that would increase bank failures. Banks understand the central bank's dilemma, and therefore from the start of the game engage in excessive investment, hence increasing equilibrium financial fragility. Third, at the end of Section 4, we analyze the central bank's problem in an infinitely repeated game. We show in the longer run how the central bank can restrict banks' aggregate investment, lower financial fragility and restore the first best solution by adhering to the socially optimal interest rate. The deviating banking sector will be punished by the central bank's best response, and we characterize the range of central bank discount rates that ensures this cooperative solution.

\subsection{A Dual Policy Tradeoff}

Modern central banks have one policy tool, the interbank interest rate $r$. However, central banks face a variety of policy objectives. For the purposes of this paper, we focus on three 
policy objectives-inflation, employment or investment, and financial stability. Since these objectives often conflict, the central bank faces a dual policy tradeoff.

The first tradeoff, between inflation and unemployment, is well documented and understood. This basic tradeoff is known as the Phillips curve, first documented by Phillips (1958), then placed in a micro-founded setting by Lucas (1972) and Woodford (2003). The Phillips curve's ramifications for central bank policy are examined by Barro and Gordon (1983). The second tradeoff, between investment and financial stability, has only been recently analyzed, see Cao and Illing (2012); Chollete and Jaffee (2012); and Kashyap and Stein (2012). The crux of this tradeoff is that an interest rate policy which encourages investment has an externality effect of excess credit supply, which in turn increases financial instability. In this paper we analyze both tradeoffs from the perspective of the central bank.

\subsection{Contributions}

Our paper contributes to the literature on optimal monetary policy by formalizing the investment fragility tradeoff faced by a central bank. We then characterize the dual tradeoff from inflation-investment-fragility that plagues monetary policy, in a simple static game. Finally, we extend our results to a dynamic game setting.

The remainder of the paper is organized in the following manner. Section 2 motivates the relationship between financial fragility and investment. Section 3 models the central bank's tradeoff between fragility and investment. Section 4 studies an extended model that accounts for feedback between the real and financial sectors, and Section 5 concludes.

\section{Motivation for Fragility-Investment Relation}

In order to motivate the dual tradeoff approach to macroprudential policy, we need a functional relation for the second tradeoff ${ }^{2}$, between fragility $f$ and aggregate investment liabilities $L$. That is, we require a simple micro-foundation for the function $f=f(L)$. A natural way to do this is to consider the well-documented fire-sale externality phenomena of banks: during normal times, banks overinvest. Since every bank does this, during extreme events the whole system is adversely affected.

\footnotetext{
${ }^{2}$ For the first tradeoff, the Phillips curve, see Phillips (1958); Lucas (1972); and Woodford (2003).
} 
There are two ways to represent such externalities: via the likelihood of extremes, or the impact of extreme events. The externality can be an excessively high likelihood of extreme events (Chollete (2012)), or an excessively high level of liabilities during extreme events (Allen and Gale (2007); Kashyap and Stein (2012)). The first method is somewhat general, so we present it in the Appendix. We focus on the liability-based approach below.

\subsection{Leverage-Based Fragility Measure}

This approach models an externality from excessive investment, as in Fisher (1933); Keynes (1936); Allen and Gale (2007); and Kashyap and Stein (2012). We summarize the approach of Kashyap and Stein (2012). Consider a large number of banks that play an infinitely repeated game, in periods denoted by $t$, for $t=0,1, \ldots \infty$. In order to model revelation of information about systemic risk fragility, each period $t$ is further subdivided into three dates $t_{0}, t_{1}$, and $t_{2}$. Every bank $i$ holds exogenously determined equity $k^{i}$, whose value is uniformly distributed over the interval $[0, K]$.

The banks are in the business of investing, which can funded in two ways-short term or long term debt. Specifically, each period the representative bank has an investment opportunity, which, during normal times, transforms investment $I^{i}$ made at initial date $t_{0}$ into $\theta I^{i}$ two dates later at $t_{2}$, for $\theta>1$. During extreme periods, investment yields no profit, and $\theta=0$. In order to fund $I^{i}$, bank $i$ may issue an amount $m I^{i}$ of short-term debt and $(1-m) I^{i}$ of long-term debt. The gross interest rates on these two types of debts are $r_{1}$ and $r_{1}+\delta$, respectively. Therefore the bank's costs in normal times are $m I^{i} r_{1}+(1-m) I^{i}\left(r_{1}+\delta\right)=$ $I^{i}\left(r_{1}+\delta-m \delta\right)$, implying net profits of $I^{i}\left(\theta-r_{1}-\delta+m \delta\right)$.

At date $t_{1}$ there is a public signal of the $t_{2}$ return from investment. With probability $1-s$ it will be a normal state in $t_{2}$, with investment return of $\theta I^{i}$, while with probability $s$ (for systemic) it will be in the crisis state, with investment return of 0 . In a normal state, debtors will roll over the banks' debt, while in a crisis state, debtors refuse to roll over debt. A bank goes bankrupt if its equity value $k^{i}$ is less than the value of short term debt $m I^{i}$ at date $t_{1}$. Since $k^{i}$ is uniformly distributed over $[0, K]$ the probability that bank $i$ goes bankrupt is simply $\frac{m I^{i}}{K}$. For simplicity, the likelihood of systemic risk is assumed to be linear in aggregate investment $I \equiv \sum_{i} I^{i}$. Similarly, the cost $C^{i}$ that each bankrupt firm imposes on society is also linear, $C^{i}=\gamma \cdot \sum_{i} I^{i}$, for $\gamma>0$. Under bankruptcy of bank $i$, its entire assets will be sold at a depressed price $p$, which applies to all other banks' assets 
and implies a cost for bank $i$ of $C^{i}=\gamma \cdot \sum_{i} I^{i}$. Thus bank $i$ 's costs during extreme periods are given by $\frac{p m I^{i} \gamma \sum I^{i}}{K}$.

Such a fire sale externality implies that each bank does not internalize the cost it imposes on the other banks, when it goes bankrupt. The problem for bank $i$ at the beginning of period $\mathrm{t}$, date $t_{0}$ is to maximize expected profit $\Pi^{i}$ :

$$
\max _{I^{i}} \Pi^{i}=I^{i}\left(\theta-r_{1}-\delta+m \delta\right)-\frac{p m I^{i} \gamma \sum_{i} I^{i}}{K}
$$

The solution to (1) is given by

$$
I^{c}=\left(\theta-r_{1}-\delta+m \delta\right) \frac{K}{p m \gamma}
$$

where the $c$ denotes the competitive outcome, and we remove superscript $i$ for simplicity. The socially optimal value maximizes joint profits $\sum_{i} \Pi^{i}=\sum_{i} I^{i}\left(\theta-r_{1}-\delta+m \delta\right)-$ $\frac{p m I^{i} \gamma \sum_{i} I^{i}}{K}$. The corresponding optimal investment ${ }^{3}$ is given by

$$
I^{p}=\left(\theta-r_{1}-\delta+m \delta\right) \frac{K}{2 p m \gamma},
$$

where $p$ denotes a Pareto optimum. Similar to the results in the above subsection, the competitive level of investment $I^{c}$ exceeds the optimum $I^{p}$.

Fragility Measure $f^{1}$. In this framework, financial fragility $f$ is represented by the probability of bankruptcy due to excess leverage. With a continuum of competitive banks, this probability is the mass of banks with capital less than $m I^{c}$, that is, $\frac{m I^{c}}{K}$. We therefore define our main fragility measure $f^{1}$, as below. The alternative fragility measure $f^{0}$ is in Appendix A.1.

Definition 1. The leverage-based fragility measure is $f^{1}(I)=\frac{m I^{c}}{K}$.

We summarize relevance of the fragility measures in Proposition 1, and the inefficiencies that motivate central bank intervention in Proposition 2, below.

Proposition 1: In a competitive banking system, financial fragility $f$ can be represented as a function of equilibrium aggregate liabilities $L=\sum_{i} l^{i}$, or as a function of aggregate bank investment $I=\sum_{i} I^{i}$.

\footnotetext{
${ }^{3}$ For further details, see p. 272 of Kashyap and Stein (2012).
} 
Proposition 2: In a competitive banking system with fire-sale externalities, the likelihoodbased fragility $f^{0}$ and the leverage-based fragility $f^{1}$ are inefficiently high.

Now that we have established the concept of financial fragility, we utilize it in the remainder of the paper in a game theoretic setup. For simplicity we use the symbol $f$ to denote fragility.

\section{Modelling Tradeoffs between Fragility, Investment and Output}

In this section we develop a simple model to fix ideas, and throughout we focus on describing the second, financial fragility tradeoff. We develop this model further in the succeeding section. Since the first tradeoff of unemployment and inflation is well understood, we utilize existing results from that literature directly. The setting is one of common knowledge, where the central bank knows the payoff functions of banks. ${ }^{4}$ The central bank interacts with banks and entrepreneurs, and plays the game repeatedly. Such repetitions are cumbersome to represent, hence we simplify computation by focusing on a stage game, which is a one-shot version of the repeated game. If the full game is played $T$ times, then the payoff for each player is just the discounted sum of the payoffs in each stage game.

Notation. This paper uses several types of notation in the next section. In order to ease the reader's understanding of the paper, we present below the most frequently used parameters and symbols.

- $a$ : Cost to central bank of missing inflation or interest target

- $b$ : Cost to central bank of missing investment target

- $\beta$ : Phillips curve-based cost to central bank of missing interest target

- $r^{*}$ : Target interest rate

- $I^{E}-I^{*}$ : Gap between optimal and target investment

- $I^{*}$ : Optimal Investment

\footnotetext{
${ }^{4}$ For earlier work, see Kydland and Prescott (1977), and Barro and Gordon (1983). For details on repeated games, see Fudenberg and Tirole (1991); Gibbons (1992); and Mas-Colell et al. (1995).
} 
- $K$ : Total equity in banking system

- $\gamma$ : Multiplier for systemic costs relative to $I$, which measures fire-sale costs

- $m$ : Fraction of short-term debt in banking system, which measures system illiquidity

- $\varepsilon_{y}:$ Output shock

- $G\left(E\left[\varepsilon_{y}^{i *}\right], \hat{r}\right)$ : the measure of banks that are expected to fail

Setting for Inflation-Unemployment Tradeoff. The background here is well studied in the literature, so we only briefly comment. There are three main actors, employers, workers and the central bank. The central bank sets the interest rate which determines money supply and inflation. In order to capture anticipated effects, employees and workers set an imperfectly indexed wage. The central bank can set the interest rate lower than expected, which will yield reduce real wages and allow employment to increase, but also yield higher inflation.

Setting for Fragility Tradeoff. There are three actors in this part: a large number of firms, a large number of financial intermediaries ('banks'), and a central bank. The setting is a sequential-move game where (time $t$ ) the entrepreneurs and banks negotiate on the level of risky loans to undertake, after which (time $t+1$ ) the central bank chooses the interbank interest rate and whether to bail out or provide liquidity to some banks that are distressed. Knowing the central bank's strategy, investors and banks will anticipate this in period $t$ when deciding their optimal strategies. In particular, if the central bank plans to rescue some distressed banks and lower interest rates, this will cause both banks and investors to demand and supply excessive risky loans, thereby increasing systemic risk. At the same time, it is beneficial to lower interest rates and rescue some banks, since this encourages investor confidence, thereby providing a spur to innovative investment that might not otherwise occur.

Consequently, when deciding on bailouts, liquidity requirements and low interest rates, the policymaker faces a fragility tradeoff. This tradeoff features costs of financial fragility and systemic instability due to excess of risky loans, and benefits of enhanced investment, to the extent that low rates and rescuing of some distressed banks cause more worthwhile innovative projects than anticipated to be undertaken. The above interaction is repeated an infinite number of times, $T=\infty$. In order to focus on this long run tradeoff, we analyze a reduced-form version of the repeated interaction, in the following stage game. 
We model financial fragility $f$ as an index that the central bank can affect directly, through its decisions on how many distressed banks to rescue, as well as the magnitude and duration of interest rate cuts. ${ }^{5}$ For simplicity, $f$ can denote the number (or fraction) of banks that will be allowed to fail during an extreme event. In the stage game below, we combine the output-inflation tradeoff with this relatively recently studied, fragility tradeoff.

\subsection{A Base Model without Feedback Effects}

First, banks and companies form expectations of financial fragility, $\hat{f}$, and inflation, $\hat{\pi}$, respectively. Second, the policymaker assesses expectations and chooses the actual fragility $f$ and inflation $\pi$. Banks and companies receive payoffs of $-(f-\hat{f})^{2}$ and $-(\pi-\hat{\pi})^{2}$, respectively. That is, banks (companies) desire to anticipate fragility (inflation) as well as possible, achieving their maximal payoff when $f=\hat{f}(\pi=\hat{\pi})$. The policymaker wishes fragility and inflation to be close to zero, but also desires investment $I$ and employment $y$ to be at efficient, ${ }^{6}$ levels $I^{*}$ and $y^{*}$.

We let the real rate $\bar{r}$ be fixed, so that by the Fisher relation $\pi=r_{1}-\bar{r}$, it is sufficient to focus on the nominal short rate $r_{1}$ instead of inflation. The policymaker's loss function is therefore

$$
\min _{r_{1}} L=\left(y-y^{*}\right)^{2}+a\left(r_{1}-r^{*}\right)^{2}+b\left[f(I)-f^{*}\right]^{2},
$$

where $a>0$ and $b>0$ reflect costs to the central bank of missing its targets. All terms in (4) depend on the interest rate $r_{1}$, in a manner that we now make explicit via the inflationoutput and fragility-investment tradeoffs, below. The inflation-output relationship is defined by the Phillips curve,

$$
y=\alpha y^{*}+\beta\left(r_{1}-\hat{r}+\varepsilon_{y}\right),
$$

\footnotetext{
${ }^{5}$ More generally, $f$ will be a vector $[f, r]$ of the fraction of banks rescued and interest rates.

${ }^{6}$ Perfect financial market stability may not be efficient, if it means no investment is undertaken.
} 
where $\alpha>0$ and $\beta>0$, and $\varepsilon_{y}$ is a zero-mean shock to output, $\varepsilon_{y} \sim\left[0, \sigma_{y}^{2}\right]$. We model the relationship between financial investment and the short-term interest rate by building on the Kashyap and Stein (2012) specification, from equation (2) above:

$$
I=\left(\theta-r_{1}-\delta+m \delta+\varepsilon_{f}\right) \frac{K}{p m \gamma} .
$$

Note that, unlike Kashyap and Stein (2012), we account for random financial shocks via the term $\varepsilon_{f}, E\left[\varepsilon_{f}\right]=0$. Financial fragility is defined as the cost of a fire sale, namely $f(I)=\gamma \bar{I}=\left(\theta-r_{1}-\delta+m \delta+\varepsilon_{f}\right) \frac{K}{p m}$. And the socially optimal financial fragility $f^{*}$ is $f^{*}=\gamma I^{*}=\gamma\left(\theta-r_{1}-\delta+m \delta+\varepsilon_{f}\right) \frac{K}{2 p m \gamma}$, or

$$
f^{*}=\left(\theta-r-\delta+m \delta+\varepsilon_{f}\right) \frac{K}{2 p m} .
$$

Therefore, the central bank's decision problem in (4) can be rewritten in terms of $r_{1}$, using (5) and (6), as

$$
\min _{r_{1}} L=\left[\alpha y^{*}+\beta\left(r_{1}-\hat{r}+\varepsilon_{y}\right)-y^{*}\right]^{2}+a\left(r-r^{*}\right)^{2}+b\left[\left(\theta-r_{1}-\delta+m \delta+\varepsilon_{f}\right) \frac{K}{2 p m}\right]^{2} .
$$

This objective is solved in Appendix A.2 to yield expressions for optimal interest rate $r^{c}$ and output $y$ :

$$
r^{c}=\frac{1}{B}\left[(1-\alpha) \beta y^{*}+a r^{*}+(\theta-\delta+m \delta) C\right]-\frac{1}{A}\left(\beta^{2} \varepsilon_{y}-C \varepsilon_{f}\right)
$$

and

$$
y=\alpha y^{*}+\frac{B}{A} \beta \varepsilon_{y}+\frac{C}{A} \beta \varepsilon_{f}=\alpha y^{*}+\frac{\beta}{A}\left(B \varepsilon_{y}+C \varepsilon_{f}\right),
$$

where the coefficients $A, B$ and $C$ capture the relative weights attached to various forms of over- or undershooting: $A=a+\beta^{2}+b\left(\frac{K}{2 p m}\right)^{2}, B=a+b\left(\frac{K}{2 p m}\right)^{2}$, and $C=b\left(\frac{K}{2 p m}\right)^{2}$. The expected welfare loss $E\left[L^{n}\right]$ is also computed in Appendix A.3, Equation (33), to be 


$$
\begin{aligned}
E\left[L^{n}\right]= & (\alpha-1)^{2} y^{* 2}+a\left[\frac{(1-\alpha) \beta y^{*}+\left(\theta-\delta+m \delta-r^{*}\right) C}{B}\right]^{2} \\
& +C\left[\frac{(1-\alpha) \beta y^{*}+a r^{*}-(\theta-\delta+m \delta) a}{B}\right]^{2} \\
& +\frac{B^{2}+\beta^{2}(a+C)}{A^{2}} \beta^{2} \sigma_{y}^{2}+\frac{\left(a+\beta^{2}\right)^{2}\left(C^{2}+C\right)}{A^{2}} \sigma_{f}^{2}+2 C \beta^{2} \frac{B+\beta^{2}}{A^{2}} \rho_{y, f},
\end{aligned}
$$

where $\sigma_{y}^{2}, \sigma_{f}^{2}$ and $\rho_{y, f}$ are the real shock variance, financial shock variance, and correlation of the two shocks, respectively. In contrast, the cooperative, expected welfare loss $E\left[L^{c}\right]$ under perfect anchoring is computed in Equation (34) of the Appendix to be

$$
E\left[L^{c}\right]=E\left[\left[(\alpha-1) y^{*}+\beta \varepsilon_{y}\right]^{2}+\left(\frac{K}{2 p m} \varepsilon_{f}\right)^{2}\right]=(\alpha-1)^{2} y^{* 2}+\beta^{2} \sigma_{y}^{2}+\frac{C}{b} \sigma_{f}^{2} .
$$

Comments on the Solution. Two aspects of the above solutions seem cogent. First, the volatility of shocks to both the financial and real sectors matter for optimal loss of the central bank. Second, and perhaps more novel, the covariance of real and financial shocks, $\rho_{y, f}$, directly affects the central bank's expected loss. In particular, it is not enough for the central bank to focus on real or financial shocks: it must also identify the dependence between real and financial shocks. We summarize this latter observation in a Proposition, below.

Proposition 3: In a dual tradeoff model, the central bank's expected loss increases monotonically with the dependence between financial and real shocks.

\subsection{Explanatory Power and Novel Implications}

Our theoretical framework provides a simple method to incorporate financial and real considerations, simultaneously, in a tractable form for central bank policy. It also offers a potential explanation of several interesting phenomena. In particular, a large, positive real economy shock $\varepsilon_{y}$ shifts the production function up and raises marginal productivity. Since marginal productivity determines marginal return on capital, banks increase their supply of 
credit. Consequently real shocks have financial effects, and our model explains the empirically observed procyclicality of credit.

Similarly, a large negative financial shock $\varepsilon_{f}$ reduces the amount of credit $I$ that banks supply. This in turn reduces investment of firms and therefore results in output contraction. Hence our model explains the empirically observed occasional spillovers from financial crises to the real economy. These spillovers will be exacerbated, the larger the correlation between real and financial shocks.

Implications. Our model also has some novel implications. In particular, it suggests a dual tradeoff between enhancing economic output and maintaining financial fragility. The reason is that the central bank's policy instrument $r_{1}$, the short rate, appears positively in the real economy, equation (10) but negatively in the financial economy, equation (11). Central banks will experience the bite of this tradeoff, the larger the investment parameter $\tau$ and the larger the correlation between real and financial shocks.

Potential Policy Tools. In light of the above analysis, effective policy instruments in the face of this dual tradeoff must decrease $\tau$ or reduce real-financial correlations $\rho_{y, f}$. One possible approach is for central banks to market correlation-indexed bonds, i.e. securities that are indexed to the level of dependence between the real and financial sector.

\section{A Model with Feedback between Banks and Firms}

Thus far, we have modeled a simple link between banks and firms, via the correlation of shocks, $\rho_{f, y}$. More realistically, banks create credit $I$ that firms use to produce real output $y$. Hence the central bank's choice of interest rate $r$ affects bank credit, which affects real output. In turn, the real output is observed, which affects the central bank's choice of interest rate.

Feedback from Financial Sector to the Real Economy. This framework allows us to account for the real effect of financial crises, since they reduce $I$ via fire sales. ${ }^{7}$ In turn, the reduced $I$ decreases real output. Hence the Phillips curve is expanded to contain another element, namely $I$.

\footnotetext{
${ }^{7}$ This approach is similar to the credit transmission channel of Bernanke and Gertler (1989).
} 
Feedback from the Real Economy to the Financial Sector. Our framework also allows us to account for feedback from the real economy, because the banking sector decide the amount of credit $I$ available depending on its expected marginal return. This marginal return, $\theta$ from the Kashyap and Stein (2012) specification, is equal in competitive markets to the marginal productivity of capital in the real economy.

We therefore revisit the Phillips curve and financial investment equations from the previous section. In light of the above observations, we propose to account for financial frictions in the real economy via an investment-augmented Phillips curve:

$$
y=\left(I-I^{*}\right)+y^{*}+\beta\left(r_{1}-\hat{r}+\varepsilon_{y}\right),
$$

where $I^{*}$ represents investment under the natural rate of output $y^{*}$. We retain our previous specification of the relationship between financial investment and the short-term interest rate from Section 3 above:

$$
I=\left(\theta(y)-r_{1}-\delta+m \delta+\varepsilon_{f}\right) \frac{K}{p m \gamma} .
$$

Hence the financial sector and real sector are linked in three ways. First, as discussed above, the two equations (10) and (11) are linked via the function $\theta(y)$, which represents the marginal return on bank capital in (11), and is determined by the marginal product of $y$ from equation (10). Second, they are linked by the available credit for investment $I$, which is a component of real output. Finally, they are linked via the short rate $r_{1}$, which is set by the central bank in response to output shock $\epsilon_{y}$.

\subsection{Formalization of the Model}

Consider a large number of banks and firms that play an infinitely repeated game with a central bank, in periods denoted $t$, for $t=0,1, \ldots,+\infty$. Each period $t$ is further subdivided into three dates $t_{0}, t_{1}$, and $t_{2}$. The timing of the model is summarized in Figure 1.

Stage $t_{0}$ : Each bank $i$ decides its loan or credit supply $I^{i}$ to the firms, given its expectation on the central bank's short-term (one-period) policy rate $\hat{r}$ and the expected output of the firms. To finance $I^{i}$, bank $i$ may issue an amount $m I^{i}$ of short-term debt and $(1-m) I^{i}$ of long-term debt, the later of which lives from $t_{0}$ to $t_{2}$. The short term debt is rolled over 
Figure 1: Timeline of Events in the Model

\begin{tabular}{|c|c|c|}
\hline$t_{0}$ & $t_{1}$ & $t_{2}$ \\
\hline $\begin{array}{l}\text { Bank } i \text { provides credit } I^{i} \text { to firms, } \\
\text { based on its expectation of central } \\
\text { bank's policy rate } \hat{r} \text {; } \\
\text { The credit } I^{i} \text { is financed by both } \\
\text { short term and long term debt } \\
\text { contract, with interest rates } r_{1} \text { and } \\
r_{1}+\delta \text {, respectively; } \\
\text { The firms use the credit to buy } \\
\text { capital input, and start production. }\end{array}$ & $\begin{array}{l}\text { The shock to the production sector } \\
\varepsilon_{y} \text { gets revealed; } \\
\text { The central bank decides its policy } \\
\text { rate } r^{E} \text {, based on the shock, } \\
\text { inflation, and cost of bankruptcies in } \\
\text { the financial sector; } \\
\text { The bank gets bankrupt if its equity } \\
\text { value becomes negative, and its } \\
\text { assets are sold at depressed price; } \\
\text { If the bank survives, it repays the } \\
\text { existing short-term debt contracts, } \\
\text { and rolls over part of the debts by } \\
\text { issuing new short-term debts with } \\
\text { interest rate } r^{E} \text {. }\end{array}$ & $\begin{array}{l}\text { The surviving banks get return from } \\
\text { its investment on the firms, and } \\
\text { repay both the short and long term } \\
\text { debt contracts; } \\
\text { The failed banks get dissolved, and } \\
\text { debts cleared. }\end{array}$ \\
\hline
\end{tabular}

at $t_{1}$ with expected rate $\hat{r}$. With similar notation to the previous section, the gross interest rates on these two types of debts are $r_{1}$ and $r_{1}+\delta$, respectively, where compounding yields $r_{1}=\hat{r}^{2}$.

The firms use the loan $I^{i}$ as an input. The return from the bank's investment on firms, $\theta$, is determined by the expected aggregate output $E[y]$, and $\theta(E[y])$ is an increasing function of $E[y]$. The bank's expected costs are therefore $C\left(m, r_{1}\right)=m I^{i} r_{1}+(1-m) I^{i}\left(r_{1}+\delta\right)$, implying expected net profits of $\theta(E[y]) I^{i}-C\left(m, r_{1}\right)$, if it survives till $t_{2}$. Without much loss of generality, assume that $\theta(E[y])=\omega E[y]$.

Stage $t_{1}$ : At $t_{1}$ there is a publicly observed signal of the aggregate shock on date $t_{2}$ 's return from firms. The shock is denoted by $\varepsilon_{y} \sim N\left(0, \sigma_{\varepsilon_{y}}^{2}\right)$. After the shock, the central bank sets its policy rate $r^{E}$, based on its loss function:

$$
\min _{r^{E}} \quad L=\left(y-y^{*}\right)^{2}+a\left(r^{E}-r^{*}\right)^{2}-\gamma \sum_{i} I^{i} G\left(E\left[\varepsilon_{y}^{i *}\right], \hat{r}\right)
$$

where the superscript $E$ denotes equilibrium. The term $G\left(E\left[\varepsilon_{y}^{i *}\right], \hat{r}\right)$ denotes the measure of banks expected to fail, which depends on both real and monetary shocks, as explained later in this section. This policy rate will affect aggregate output at $t_{2}$. Actual output 
is determined by the input $I$, subject to price stickiness. We define this inflation-output relationship by an "augmented" Phillips curve

$$
y\left(r^{E}, \varepsilon_{y}\right)=\left(I-I^{*}\right)+y^{*}+\beta\left(r^{E}-\hat{r}+\varepsilon_{y}\right) .
$$

The investment under natural output is denoted by $I^{*}$. Without loss of generality, the natural output is normalized as $y^{*}=I^{*}$.

In a state when the bank's return is higher than $r^{E}$, debtors will roll over the banks' debt, while in other states, debtors refuse to roll over debt. The bank goes bankrupt if its equity value $k^{i}$ (uniformly distributed on $[0, K]$ ) is less than the value of short term debt $m I^{i}$ net the expected value of its assets at date $t_{2}$. If the bank goes bankrupt, its entire assets will be on fire sale, subject to the fire sale cost.

Stage $t_{2}$ : If the bank survives, the firms will repay the loans, and the debtors withdraw.

The equilibrium of the model is featured by the following set of functions:

(1) Given $r^{E}$, the firms' aggregate output at $t_{2}$ is $y=\left(I-I^{*}\right)+y^{*}+\beta\left(r^{E}-\hat{r}+\varepsilon_{y}\right)$, implying that the gross return to the bank's investment is $\theta=\omega y$.

At $t_{1}$, the bank will go bankrupt if $m I^{i} \hat{r} r^{E}+(1-m) I^{i}\left(r_{1}+\delta\right)-\omega y I^{i}>k^{i}$. Define $y^{i *}$ and $\varepsilon_{y}^{i *}$ such that $m I^{i} \hat{r} r^{E}+(1-m) I^{i}\left(r_{1}+\delta\right)-\omega y^{i *} I^{i}=k^{i}$, and $y^{i *}=\left(I-I^{*}\right)+y^{*}+$ $\beta\left(r^{E}-\hat{r}+\varepsilon_{y}^{i *}\right)$. Then the ex post probability that the bank goes bankrupt is $G\left(\varepsilon_{y}^{i *}\right)$.

(2) If the bank goes bankrupt at $t_{1}$, its assets will be sold at the depressed price. The fire sale cost is $\gamma \sum_{i} I^{i}$.

At $t_{0}$ the bank's optimal decision on investment is determined by maximizing its profit

$$
\max _{I^{i}} L_{B}^{i}=\omega(E[y]) I^{i}-C\left(m, r_{1}\right)-\gamma \sum_{i} I^{i} G\left(E\left[\varepsilon_{y}^{i *}\right], \hat{r}\right)
$$

where the $B$ superscript denotes the bank, $G\left(E\left[\varepsilon_{y}^{i *}\right], \hat{r}\right)$ denotes the ex ante probability of bankruptcy, and rational expectations implies that $\hat{r}=E\left[r^{E}\right]$.

At stage $t_{0}$ the following relation holds: $\omega(E[y])=\omega E\left[\left(I-I^{*}\right)+y^{*}+\beta\left(r^{E}-\hat{r}+\varepsilon_{y}\right)\right]=$ $\omega I$, where $I$ is the aggregate credit supply, taken as given for each individual bank. 
Given the bank's expectation on central bank policy, $\hat{r}$, the bank's expected probability of becoming bankrupt ${ }^{8}$ at $t_{1}$ is $G\left(E\left[\varepsilon_{y}^{i *}\right], \hat{r}\right)=\frac{m I^{i} \hat{r}^{2}+(1-m) I^{i}\left(r_{1}+\delta\right)-\omega I I^{i}}{K}$. Therefore, the bank's optimal decision problem at $t_{0}$ is

$\max _{I^{i}} L_{B}^{i}=\omega I I^{i}-m I^{i} r_{1}-(1-m) I^{i}\left(r_{1}+\delta\right)-\gamma \sum_{i} I^{i} \frac{m I^{i} \hat{r}^{2}+(1-m) I^{i}\left(r_{1}+\delta\right)-\omega I I^{i}}{K}$

Note that since we are in a two period model, the short rate $\hat{r}$ and long rate $r_{1}$ are related by $r_{1}=\hat{r}^{2}$.

Bank's Competitive Equilibrium Outcome $I^{E}$. Under the above assumptions, the bank's first order condition yields

$$
\frac{\partial L_{B}^{i}}{\partial I^{i}}=\omega I-m r_{1}-(1-m)\left(r_{1}+\delta\right)-\gamma I \frac{m \hat{r}^{2}+(1-m)\left(r_{1}+\delta\right)-\omega I}{K}=0 .
$$

This condition is satisfied by the equilibrium investment $I^{E}$ such that

$$
\omega I^{E} K-r_{1} K-K \delta+K m \delta-\gamma I^{E} r_{1}-\gamma I^{E} \delta+\gamma I^{E} m \delta+\gamma\left(I^{E}\right)^{2} \omega=0,
$$

where the superscript $E$ denotes equilibrium. However, the bank does not take into account the fire sale externality it imposes to the entire financial system, which leads to excessive investment.

Bank's Social Optimum $I^{p}$. We now account for fire-sale externalities. If a planner forces the bank to consider fire sale costs, the bank will solve the following decision problem:

$$
\max _{I^{p}} L_{B}^{p}=\omega\left(E\left[y\left(I^{p}\right)\right]\right) I^{p}-C\left(m, r_{1}\right)-\gamma \sum_{i} I^{p} G\left(\varepsilon_{y}^{i *}, \hat{r}\right)(i)
$$

where the superscript $p$ denotes planner. This maximization problem can be rewritten

$$
\max _{I^{p}} L_{B}^{p}=\omega\left(I^{p}\right)^{2}-m I^{p} r_{1}-(1-m) I^{p}\left(r_{1}+\delta\right)-\gamma I^{p} \frac{m I^{p} \hat{r}^{2}+(1-m) I^{p}\left(r_{1}+\delta\right)-\omega\left(I^{p}\right)^{2}}{K} .
$$

\footnotetext{
${ }^{8}$ Our formulation of $G()$ therefore generalizes the Kashyap and Stein (2012) framework, since the short rate enters $G()$. This formalizes the notion that the central bank can affect the likelihood of default.
} 
The first order condition yields

$\frac{\partial L_{B}^{p}}{\partial I^{p}}=2 \omega I^{p}-m r_{1}-(1-m)\left(r_{1}+\delta\right)-\frac{2 \gamma I^{p} m \hat{r}^{2}+2 \gamma I^{p}(1-m)\left(r_{1}+\delta\right)-3 \gamma \omega\left(I^{p}\right)^{2}}{K}=0$,

or the $I^{p}$ such that

$$
2 I^{p} \omega K-r_{1} K-K \delta+K m \delta-2 I^{p} \gamma r_{1}-2 I^{p} \gamma \delta+2 I^{p} \gamma m \delta+3\left(I^{p}\right)^{2} \gamma \omega=0 .
$$

As summarized in Proposition 4 below, the bank's equilibrium investment is larger than the social optimum, the latter of which accounts for excess fragility.

\section{Proposition 4: Inefficiency of Bank's Competitive Equilibrium Investment.}

Part A: In market equilibrium, the bank's investment is larger than the planner's solution, i.e., $I^{E}>I^{p}$. Moreover, $\sqrt{3} I^{p}<I^{E}<2 I^{p}$.

Part B: In market equilibrium, liquidity risk provides some market discipline, but investment is still excessive.

Part A is straightforward, and provides a bound on magnitude of over-investment. Part $\mathrm{B}$ of the proposition says that a higher share of short term debt (higher $m$ ) reduces the banks' investment. Equivalently, liquidity risk restricts banks' risk-taking in the market equilibrium, thereby providing some market discipline. Nevertheless, due to the fire sale externality, market discipline is not sufficient. Compared with the planner's solution, the competitive equilibrium still features excessive investment.

Central Bank's Decision. We now derive the central bank's optimal strategy for short rates. To fix ideas, we focus on the case where banks choose the fragility-based excessive credit supply $I^{E}$ solved above. ${ }^{9}$ The central bank's optimal decision at $t_{1}$, after observing $\varepsilon_{y}$, is to solve the following program:

$$
\min _{r^{E}} L_{C}=\left(y-y^{*}\right)^{2}+a\left(r^{E}-r^{*}\right)^{2}+b \gamma \sum_{i} I^{i} G\left(\varepsilon_{y}^{i *}\right)(i)
$$

where the subscript $C$ denotes central bank. The actual output $y$, given the announced $r^{E}$, is $\left(I-I^{*}\right)+y^{*}+\beta\left(r^{E}-\hat{r}+\varepsilon_{y}\right)$, and the return of the banks' investment is therefore $\omega y$.

\footnotetext{
${ }^{9}$ Given the symmetric structure of the problem, the central bank will solve the same program when banks supply the socially optimal credit $I^{p}$, except that everywhere in the program it would replace $I^{E}$ with $I^{p}$.
} 
From the Appendix A.4, the central bank's optimal short rate $r^{E}$ is proved to satisfy

$$
r^{E}=\frac{2 a K}{2 a K+b \gamma\left(I^{E}\right)^{2} m} r^{*}-\frac{2 \beta K\left(I^{E}-I^{*}\right)}{2 a K+b \gamma\left(I^{E}\right)^{2} m}+\frac{b \gamma\left(I^{E}\right)^{2} \omega \beta}{2 a K+b \gamma\left(I^{E}\right)^{2} m}-\frac{\beta^{2}}{a+\beta^{2}} \varepsilon_{y} .
$$

The solution for $r^{E}$ in (14) can be related to extant models. For example, as in Barro and Gordon (1983), $r^{E}$ should partially respond to demand shocks, which is intuitive. There are, however, some important differences between $r^{E}$ and the short rate obtained by a traditional central bank concerned with inflation targeting. We discuss these differences below.

\subsection{Implications for Macroprudential Policy}

In conventional inflation-targeting frameworks, the central bank's decision problem does not account for fire sales. Specifically, the central bank's problem is

$$
\min _{r^{0}} L=\left[\left(I^{E}-I^{*}\right)+\beta\left(r^{0}-\hat{r}+\varepsilon_{y}\right)\right]^{2}+a\left(r^{0}-r^{*}\right)^{2}
$$

in which $r^{0}$ is the policy rate set by a pure inflation targeting central bank. The first order condition yields

$$
\frac{\partial L}{\partial r^{0}}=2 \beta\left[\left(I^{E}-I^{*}\right)+\beta\left(r^{0}-\hat{r}+\varepsilon_{y}\right)\right]+2 a\left(r^{0}-r^{*}\right)=0,
$$

or

$$
r^{0}=\frac{a r^{*}+\beta^{2} \hat{r}-\beta^{2} \varepsilon_{y}-\beta\left(I^{E}-I^{*}\right)}{a+\beta^{2}} .
$$

The consistency condition $E\left[r^{0}\right]=\hat{r}$ implies that $\hat{r}=E\left[r^{0}\right]=E\left[\frac{a r^{*}+\beta^{2} \hat{r}-\beta^{2} \varepsilon_{y}-\beta\left(I^{E}-I^{*}\right)}{a+\beta^{2}}\right]=$ $\frac{a r^{*}+\beta^{2} \hat{r}-\beta\left(I^{E}-I^{*}\right)}{a+\beta^{2}}$, or $\hat{r}=r^{*}-\frac{\beta}{a}\left(I^{E}-I^{*}\right)$. By substituting this condition into the expression for $r^{0}$, we obtain the optimal short rate $r^{0}$ for an inflation-targeting central bank: 


$$
r^{0}=r^{*}-\frac{\beta}{a}\left(I^{E}-I^{*}\right)-\frac{\beta^{2}}{a+\beta^{2}} \varepsilon_{y}
$$

Recall that for a central bank which takes financial stability into account, the optimal short rate $r^{E}$ from (14) satisfies

$$
r^{E}=\frac{2 a K}{2 a K-b \gamma\left(I^{E}\right)^{2} m} r^{*}-\frac{2 \beta K\left(I^{E}-I^{*}\right)}{2 a K-b \gamma\left(I^{E}\right)^{2} m}+\frac{b \gamma\left(I^{E}\right)^{2} \omega \beta}{2 a K+b \gamma\left(I^{E}\right)^{2} m}-\frac{\beta^{2}}{a+\beta^{2}} \varepsilon_{y}
$$

Observations on the Solution. By comparing the solution for $r^{0}$ in (15) to the one for $r^{E}$ above, we can see the role of financial stability in the central bank's decision making. In particular, we discern two effects.

First is the stability effect: in the first term of $r^{E}, \frac{2 a K}{2 a K-b \gamma\left(I^{E}\right)^{2} m}<1$, indicating that the central bank's "stability target" interest rate should be lower, once it cares about financial fragility. Thus, the central bank has the incentive to lower the policy rate in order to reduce the bankruptcy rate in the banking sector.

Second is a discipline effect: in the second term of $r^{E},-\frac{2 \beta K\left(I^{E}-I^{*}\right)}{2 a K-b \gamma\left(I^{E}\right)^{2} m}+\frac{b \gamma\left(I^{E}\right)^{2} \omega \beta}{2 a K+b \gamma\left(I^{E}\right)^{2} m}>$ $-\frac{\beta}{a}\left(I^{E}-I^{*}\right)$, indicating that the central bank's target rate should be higher, in order to restrict excessive investment. This effect is in line with suggestions by John Taylor and others, who argued in 2008 that a central bank which is concerned about financial stability should set higher policy rates (relative to the Taylor rule) in normal times, in order to deter build-up of financial imbalances. Here we do see such an incentive.

More broadly, these findings extend the literature on central bank independence (e.g. Rogoff (1985)). This literature argues that in order to achieve price stability, monetary policy should be delegated to a "conservative" central bank that only cares about inflation or, in the context of our model, $a \rightarrow+\infty$. In such a case, our model implies the following condition: $\lim _{a \rightarrow+\infty} r^{0}=r^{E}=r^{*}$.

What does our solution imply about dynamics? There is obviously the potential for moral hazard. If banks have a systematically lower expectation $\hat{r}$ and higher $I^{i}$ at $t_{0}$, the central bank will be, ex post, forced to follow with a lower $r^{E}$ if it has a low discount factor. We discuss this issue further in the repeated game formulation below. 


\subsection{An Impossibility Result}

Our framework may be valuable to clarify the limitations on central banking imposed by attempts to control both inflation and fragility. Intuitively, the only time a central bank's dual targets of inflation control and stability are compatible is when the policy rates $r^{E}$ and $r^{O}$ are equal. The central bank can use the same rate to control both inflation and targeting only if $r^{E}-r^{O}$ is identically zero. We solve this condition in the Appendix, which yields the following Proposition:

Proposition 5: General Impossibility of both Fragility Control and Inflation Commitment. Even if a central bank is independent, it is generally unable to control simultaneously fragility and inflation. Such control is only possible in the knife-edge case of $r^{*}=\frac{\beta}{a}\left(I^{E}-I^{*}\right)+\frac{\omega \beta}{m}$, i.e. where the target rate is a specific linear function of the investment gap.

\subsection{Infinitely Repeated Game}

Now consider the following infinitely repeated version of the above game. One solution above sets the vector $\left[I^{E}, r^{E}\right]$ such that, given banks' expectations, the marginal cost and benefits to the central bank from surprise investment offset each other. This outcome is subgame perfect, since the central bank is expected to allow a positive amount of fragility and indeed does so. However, the central bank would be better off if it could commit to a socially optimal scenario of $r^{p}$ (where $r^{p} \neq r^{E}$ ) that induces the optimal credit supply $I^{p}$. This is an inherent inconsistency problem, since the policymaker and banks have an incentive to deviate from the socially optimal investment and short rate $\left[I^{p}, r^{p}\right]$. A simple way to assess the implications of such deviations is to examine an infinite horizon game.

Infinite Game Formulation. Let policymakers, firms and banks share a common discount factor $d$. To solve this game, we shall clarify the player payoffs and focus on pure strategies, then derive conditions under which $r=\hat{r}=r^{p}$ and $I=I^{p}$ every period, in a subgame perfect Nash equilibrium.

Payoff functions for Central Bank and Banks. Denote the banks' choice of credit supply in equilibrium and under the social (planner) optimum as $I^{E}$ and $I^{p}$, respectively. Then the central bank's payoff as a function of short rates and the banks' credit supply $I^{i} \in\left\{I^{E}, I^{p}\right\}$, from the previous section, is 


$$
\begin{aligned}
L_{C}\left(r^{c}, \hat{r}, I^{i}\right)= & {\left[\left(I^{i}-I^{*}\right)+\beta\left(r^{c}-\hat{r}+\varepsilon_{y}\right)\right]^{2}+a\left(r^{c}-r^{*}\right)^{2} } \\
& +b \gamma I^{i} \frac{m I^{i} \hat{r} r^{c}+(1-m) I^{i}\left(r_{1}+\delta\right)-\omega\left[I^{i}+\beta\left(r^{c}-\hat{r}+\varepsilon_{y}\right)\right] I^{i}}{K},
\end{aligned}
$$

where $r^{c} \in\left\{r^{E}, r^{p}\right\}$. The bank's payoff function is

$L_{B}\left(\hat{r}, I^{i}\right)=\omega I I^{i}-m I^{i} r_{1}-(1-m) I^{i}\left(r_{1}+\delta\right)-\gamma \sum_{i} I^{i} \frac{m I^{i} r_{1}+(1-m) I^{i}\left(r_{1}+\delta\right)-\omega I I^{i}}{K}$.

We shall use the payoffs in (16) and (17) to compute optimal strategies and credible punishments for deviations.

Strategies for the Central Bank and Bank. Given a bank's credit supply $I^{i} \in\left\{I^{E}, I^{p}\right\}$, the central bank's optimal interest rate strategy, from the previous section, is given by

$$
r^{c}=\frac{2 a K}{2 a K+b \gamma\left(I^{i}\right)^{2} m} r^{*}-\frac{2 \beta K\left(I^{i}-I^{*}\right)}{2 a K+b \gamma\left(I^{i}\right)^{2} m}+\frac{b \gamma\left(I^{E}\right)^{2} \omega \beta}{2 a K+b \gamma\left(I^{E}\right)^{2} m}-\frac{\beta^{2}}{a+\beta^{2}} \varepsilon_{y} .
$$

Also from the previous section, the bank's equilibrium strategy for investment is $I^{E}$ such that the following relation holds:

$$
\omega I^{E} K-K r_{1}-K \delta+K m \delta-\gamma I^{E} r_{1}-\gamma I^{E} \delta+\gamma I^{E} m \delta+\gamma\left(I^{E}\right)^{2} \omega=0 .
$$

By contrast, the socially optimal investment $I^{p}$ allows for fire sale externalities, and $I^{p}$ is such that the following relation holds:

$$
2 \omega I^{p} K-K r_{1}-K \delta+K m \delta-2 \gamma I^{p} r_{1}-2 \gamma I^{p} \delta+2 \gamma I^{p} m \delta+3 \gamma\left(I^{p}\right)^{2} \omega=0 .
$$

The central bank wishes to encourage socially optimal investment $I^{p}$ defined in (20), and stop intermediary banks from doing $I^{E}$ in (19). To accomplish this objective, the central bank can choose a trigger strategy, which sets $r^{c}=r^{p}$ computed from (18), as long as the intermediaries behave and choose credit supply equal to $I^{p}$. Otherwise, the central bank assumes banks are going to do their most profitable deviation of $I^{E}$ and sets $r$ equal to the best response $r^{E}$, computed from (18). In our model, the banks' expectations are correct 
on average, so $I^{E}$ and $I^{p}$ are in turn best responses to $r^{E}$ and $r^{p}$, respectively. Thus the central bank's strategy is supported in subgame perfect Nash equilibrium.

The repeated game involves evaluating stage game payoffs to various strategies from the central bank and bank. These payoffs may be represented in the following matrix, Table 1 . In Table $1, L_{C}^{p}(\cdot)$ denotes the central bank's payoff in the socially optimal setting (where financial fragility is minimized), and $L_{C}^{E}(\cdot)$ denotes the central bank's payoff in the inefficient equilibrium, where financial fragility is a problem. The tilde denotes payoffs from a deviation. Thus $\tilde{L_{B}^{E}}$ is what the bank obtains by deviating to the equilibrium investment $I^{E}$.

Table 1: Stage Game Payoffs to Central Bank and Intermediary Bank

\begin{tabular}{ll|l|l} 
& & \multicolumn{2}{|c}{ Bank } \\
& & Cooperate $: r=r^{p}$ & Deviate $: r=r^{E}$ \\
\hline $\begin{array}{l}\text { Central } \\
\text { Bank }\end{array}$ & $I=I^{p}$ & $\left(\tilde{L}_{C}^{p}, \tilde{L}_{B}^{p}\right)$ & $\left(\tilde{L_{C}^{E}}, \tilde{L_{B}^{E}}\right)$ \\
\hline & $\begin{array}{l}\text { Deviate: } \\
I=I^{E}\end{array}$ & $\left(\tilde{L_{C}^{p}}, \tilde{L_{B}^{E}}\right)$ & $\left(L_{C}^{E}, L_{B}^{E}\right)$ \\
& & & \\
\hline
\end{tabular}

More specifically, we consider two types of subgames that the central bank faces. The first type is one in which banks have chosen the socially optimal credit supply $I^{p}$ and the central bank sets the short rate to $r^{c}$ in (18), for the present and for all previous periods. The second type is any one in which intermediary banks have deviated by choosing the individually rational but fire-sale provoking credit level $I^{E}$. The central bank and intermediary bank share a common discount factor $d$.

Banks: In the first period, banks hold the expectation $\hat{r}=r^{p}$, and supply the socially optimal credit $I^{p}$. In subsequent periods they expect $\hat{r}=r^{p}$, if and only if all prior credit supply was $I^{p}$ and short rates were actually $r^{p}$. Otherwise, bank expectations $\hat{r}$ are set equal to $r^{E}$, which we defined as optimal for the central bank if it wants to punish banks for excess credit supply in the stage game.

Central Bank: The central bank chooses $r=r^{p}$ if and only if current bank and firm expectations satisfy $\hat{r}=r^{p}$, all previous expectations have been $\hat{r}=r^{p}$, and all previous 
actual investment and short rates have been $I^{p}$ and $r^{p}$. Otherwise, the central bank assumes banks are building up excess credit $I^{E}$ and chooses $r^{c}=r^{E}$ from its best response (18).

Infinite Game Equilibrium. Let banks' first-period expectations be $\hat{r}=r^{p}$. Further, as in Table 1, denote the central bank's loss function as $L_{C}^{p}\left(r^{p}, I^{p}\right)$. Now, given the bank's strategy, the central bank can focus on two possible paths of financial fragility. The first path involves $\hat{r}=r^{p}$, which results the next period in $\hat{r}=r^{p}$ and $I^{p}$. Consequently the central bank makes the same decision next period. The second alternative involves expectations $\hat{r}=r^{E}$ and credit supply $I=I^{E}$. This results in $\left(I^{E}, r^{E}\right)$ forever.

The payoffs from these two strategies are as follows. The first strategy $\left(r=r^{p}\right.$ this period), yields the central bank a payoff of $L_{C}^{p}\left(r^{p}, I^{p}\right)$ forever, for a total of $\frac{1}{1-d} L_{C}^{p}\left(r^{p}, I^{p}\right)$. The second strategy $\left(r=r^{E}\right.$ this period) yields the central bank ${\tilde{L_{C}^{p}}}_{C}\left(r^{p}, I^{p}\right)$ this period, then $L_{C}^{E}\left(r^{E}, I^{E}\right)$ forever, for a total of $\tilde{L_{C}^{p}}\left(r^{p}, I^{p}\right)+\frac{d}{1-d} L_{C}^{E}\left(r^{E}, I^{E}\right)$. Therefore the central bank's strategy is a best response to the banks' strategy if the following condition holds: $\frac{1}{1-d} L_{C}^{p}\left(r^{p}, I^{p}\right) \geq \tilde{L_{C}^{p}}\left(r^{p}, I^{p}\right)+\frac{d}{1-d} L_{C}^{E}\left(r^{E}, I^{E}\right)$. This condition can be rewritten as

$$
d \geq \frac{\tilde{L_{C}^{p}}\left(r^{p}, I^{p}\right)-L_{C}^{p}\left(r^{p}, I^{p}\right)}{\tilde{L}_{C}^{p}\left(r^{p}, I^{p}\right)-L_{C}^{E}\left(r^{E}, I^{E}\right)},
$$

which has a ready economic implication. Economically speaking, the central bank finds it optimal not to deviate from its commitment to minimize future financial fragility and if and only if its discount rate (i.e. its willingness to sacrifice present pain for future gain from enforcing low fragility) is large enough.

\subsection{Discount Rate, Investment and Policy Surfaces}

In order to illustrate our results visually, we depict the threshold discount rate $d$, aggregate investment $I$, and the optimal policy rate in traditional and fragility-based settings, i.e. equations (19) and (20), respectively. This communicates the difference between our approach and previous research in an intuitive manner.

Details of our calibration are in the Appendix. ${ }^{10}$ The surface for the threshold discount rate is displayed in Figure 2. Intuitively, $d$ is more likely to be below 1 when the weight of financial stability gets higher in the central bank's loss function. We show results of

\footnotetext{
${ }^{10}$ Solution of the equations was performed in Maple.
} 
our investment calibration in Figure 3. Evidently investment is too low and unresponsive when the central bank only targets inflation. Figure 4 displays the optimal short rate for a central bank that cares about fragility or only inflation. The yellow surface shows that the optimal short rate is unresponsive to fragility concerns, which is straightforward. The dark blue surface corresponds to a relatively large $m$ (illiquidity). It is lower than the case (light blue) of small $m$, indicating attenuation of optimal short rates in the case of a highly illiquid financial sector. In sum, the calibration results are quite reasonable. Nevertheless, we do not place much emphasis on this aspect of the paper, since our focus is to illustrate, in a tractable theoretical framework, the forces at work when a central bank faces the dual tradeoffs of inflation and fragility.

\section{Conclusions}

We develop a framework that characterizes central banks' dual tradeoff between financial stability and inflation control. We analyze two models: a base model where there is no feedback, and an extended model with feedback effects between the real and financial sectors. The base model offers a potential explanation of several interesting phenomena. In particular, a large, positive real economy shock shifts the production function up and raises marginal productivity. Since marginal productivity determines marginal return on capital, banks increase their supply of credit. Consequently real shocks have financial effects, and our model explains the empirically observed procyclicality of credit. Similarly, a large negative financial shock reduces banks' credit banks supply. This in turn reduces investment of firms and therefore results in output contraction. Hence our model explains the empirically observed occasional spillovers from financial crises to the real economy. These spillovers will be more prominent, the larger the correlation between real and financial shocks.

In the extended model, we account for both intermediaries' and central banks' incentives to deviate from appropriate bailout, liquidity, and interest rate targets. Our model introduces a novel tradeoff between enhancing economic output and maintaining financial stability. Central banks will experience the bite of this tradeoff, the larger the correlation between real and financial shocks. Specifically, higher interest rates deter buildup of financial imbalances, but lower rates reduce the likelihood of bankruptcy. We term these factors the discipline effect and stability effect, respectively. We show that the central bank's welfare 
loss increases with dependence between the real and financial shocks. Thus, a central bank may be able to reduce tradeoff costs by marketing correlation-indexed securities.

Our findings extend the literature on central bank independence (e.g. Rogoff (1985)). This literature demonstrates that in order to achieve price stability, monetary policy should be delegated to a conservative central bank that only cares about inflation. Our framework suggest a further impossibility result: even with an independent central bank, the attainment of both low inflation and financial stability is in general not possible. 


\section{References}

Allen, F., Carletti, E., Gale, D., 2009. Interbank market liquidity and central bank intervention. Journal of Monetary Economics 56 (5), 639-652.

Allen, F., Gale, D., 2007. Understanding Financial Crises. Clarendon Lectures in Finance. Oxford University Press.

Barro, R., Gordon, D., 1983. Rules, discretion, and reputation in a model of monetary policy. Journal of Monetary Economics 12, 101-121.

Bernanke, B., Gertler, M., 1989. Agency costs, net worth, and business fluctuations. American Economic Review 79 (1), 14-31.

Cao, J., Illing, G., 2012. "interest rate trap", or: Why does the central bank keep the policy rate too low for too long time? Tech. rep., Norwegian Central Bank.

Chollete, L., 2012. A model of endogenous extreme events. Tech. rep., UiS Business School.

Chollete, L., Jaffee, D., 2012. Financial implications of extreme and rare events. Tech. rep., University of Stavanger.

Cornes, R., Sandler, T., 1996. The Theory of Externalities, Public Goods and Club Goods, Second Edition. Cambridge University Press, New York.

Fisher, I., 1933. The debt-deflation theory of great depressions. Econometrica 1 (4), 337-357.

Freixas, X., Parigi, B., Rochet, J., 2000. Systemic risk, interbank relations, and liquidity provision by the central bank. Journal of Money, Credit and Banking 32 (3, part 2), 611-638.

Fudenberg, D., Tirole, J., 1991. Game Theory. MIT Press, Cambridge, MA.

Gibbons, R., 1992. Game Theory for Applied Economists. Princeton University Press, New Jersey.

Kashyap, A., Stein, J., 2012. Optimal conduct of monetary policy with interest on reserves. American Economic Journal: Macroeconomics 4, January (1), 266-282.

Keynes, J., 1936. The General Theory of Employment, Interest and Money. Harcourt, Brace, and Company, New York.

Kydland, F., Prescott, E., 1977. Rules rather than discretion: The inconsistency of optimal plans. Journal of Political Economy 85, 473-491.

Lucas, R., 1972. Expectations and the neutrality of money. Journal of Economic Theory 4, 103-124.

Mas-Colell, A., Whinston, M., Green, J., 1995. Microeconomic Theory. Oxford Press.

Phillips, A., 1958. The relation between unemployment and the rate of change of money wage rates in the united kingdom, 1861-1957. Economica XXV, 283-299. 
Rogoff, K., 1985. The optimal degree of commitment to an intermediate monetary target. Quarterly Journal of Economics 100, 1169-1189.

Shin, H., 2010. Risk and Liquidity. Oxford University Press, New York.

Woodford, M., 2003. Interest Rates and Prices: Foundations of a Theory of Monetary Policy. Princeton University Press, Princeton, New Jersey. 


\section{A Appendix}

\section{A.1 Alternative Fragility Measure $f^{0}$, and Proofs of Propositions 1 and 2}

This approach observes that individual banks may not consider the full impact of their individual risk-taking on the aggregate likelihood of extreme events. The mechanism can be elucidated with a simple externality model (Cornes and Sandler (1996)), as in Chollete (2012). Consider an economy populated with a large number $N$ of small banks, indexed by $i=1, \ldots N$. All banks maximize the same expected yield function $Y$. The banks choose their assets $a^{i}$ and liabilities $l^{i}$, and aggregate liabilities $L$ are simply the sum of individual liabilities, $L \equiv \sum_{i} l^{i}$. Since banks are small, they cannot control other banks' behavior, and take the total of other banks' liabilities, $L^{-i} \equiv \sum_{j \neq i} l^{j}$, as given. The 'price' of holding one unit of assets is the foregone interest $r$, while the price of holding liabilities is the bankruptcy cost $b$ in event of a default.

Welfare Effects of Competitive Banking. We first examine the competitive solution. The typical bank's problem is to choose a combination of assets $a^{i}$ and liabilities $l^{i}$ to maximize expected yield, $Y\left(a^{i}, l^{i}, s(L)\right)$. The function $Y(\cdot)$ is concave and continuously differentiable, and the last term $s$ represents the likelihood of systemic risk. As the total amount of liabilities $L$ rises, it increases the likelihood of systemic risk. This effect occurs for a number of reasons (liquidity-mismatch, changing investor confidence, etc.), which we summarize with a continuously differentiable function $s=s(L)$. Partial derivatives are denoted with a subscript, for example, $Y_{a} \equiv \partial Y / \partial a$. In order to capture the fact that systemic risk increases with total liabilities, let $s_{L} \equiv s^{\prime}(L)>0 .{ }^{11}$ Since banks are averse to systemic risk, we let $Y_{s} \equiv \partial Y / \partial s<0$. Now the representative bank solves the following problem:

$$
\max _{\left\{a^{i}, l^{i}\right\}} Y\left[a^{i}, l^{i}, s\left(l^{i}+L^{-i}\right)\right]
$$

subject to

$$
r \cdot a^{i}+b \cdot l^{i} \leq k^{i}
$$

where $k^{i}$ is the initial capital of bank $i$. In a competitive industry, excess profits will be eroded such that (23) becomes an equality. Under the given assumptions, the bank's problem has a solution, with the following necessary and sufficient conditions: $Y_{a}^{i}-\lambda \cdot r=0$ and $Y_{l}^{i}+Y_{s}^{i} s_{L}(L)-\lambda \cdot b=0$. These conditions combine to yield $\frac{Y_{l}^{i}+Y_{s}^{i} s_{L}(L)}{Y_{a}^{i}}=\frac{b}{r}$, which can be simplified in terms of the likelihood of systemic risk as

$$
s_{L}^{c}\left(L^{c}\right)=\frac{Y_{a}^{i} \cdot \frac{b}{r}-Y_{l}^{i}}{Y_{s}^{i}},
$$

where the superscript $c$ denotes the competitive solution. The above relation characterizes sensitivity of the banking industry to increased likelihood of systemic risk, for a unit increase in total liabilities $L$, at the competitive optimum. Thus, it captures a measure of financial fragility.

\footnotetext{
${ }^{11}$ A similar approach is used in Shin (2010).
} 
In order to assess efficiency of the competitive solution above, we compute a Pareto optimum. A social planner calculates the socially optimal level of investment by solving the following optimization program:

$$
\max _{\left\{a^{i}, l^{i}\right\}} \sum_{i=1}^{N} Y^{i}\left[a^{i}, l^{i}, s(L)\right]
$$

subject to

$$
r \sum_{i} a^{i}+b \sum_{i} l^{i} \leq \sum_{i} k^{i}
$$

The solution involves the following first order conditions: $Y_{a}^{i}-\lambda \cdot r=0$, all $i$, and $Y_{l}^{i}+\left(\sum_{j} Y_{s}^{j}\right)$. $s_{L}(L)-\lambda \cdot b=0$, which combine to yield $\frac{Y_{l}^{i}+\left(\sum_{j} Y_{s}^{j}\right) \cdot s_{L}(L)}{Y_{a}^{i}}=\frac{b}{r}$. Further simplification results in the Pareto optimum condition for aggregate liabilities:

$$
s_{L}^{*}\left(L^{*}\right)=\frac{Y_{a}^{i} \cdot \frac{b}{r}-Y_{l}^{i}}{\left(\sum_{j} Y_{s}^{j}\right)},
$$

where the superscript * denotes a Pareto optimum. Evidently, (26) differs from the competitive solution in (24) by dint of the larger denominator. Thus, $s_{L}^{*}\left(L^{*}\right)<s_{L}^{c}\left(L^{c}\right)$.

General Fragility Measure $f^{0}$. The discussion above shows that the sensitivity $s_{L}(L)$ of the economy to systemic risk is suboptimally large in a competitive banking system. Since $s_{L}^{c}\left(L^{c}\right)$ measures sensitivity of the banking sector to systemic risk, we use it to define our general fragility measure $f^{0}$, as below.

Definition 2. The likelihood-based fragility measure is $f^{0}(L)=s_{L}^{c}\left(L^{c}\right)$.

Proofs of Propositions 1 and 2:

Proposition 1: In a competitive banking system, financial fragility $f$ can be represented as a function of equilibrium aggregate liabilities $L=\sum_{i} l^{i}$, or as a function of aggregate bank investment $I=\sum_{i} I^{i}$

Proof of Proposition 1. By Definition 1 in Section 2 and Definition 2 above.

Proposition 2: In a competitive banking system with fire-sale externalities, the likelihood-based fragility $f^{0}$ and the leverage-based fragility $f^{1}$ are inefficiently high.

Proof of Proposition 2. Inefficiency of $f^{0}$ follows from comparing equations (24) and (26) above. Inefficiency of $f^{1}$ follows from comparing equations (2) and (3) in Section 2. 


\section{A.2 Derivation of Optimal Policy Response $r^{c}$ of Section 3.1}

Recall from equation (7) that the the central bank's decision problem is

$$
\min _{r} L=\left[\alpha y^{*}+\beta\left(r-\hat{r}+\varepsilon_{y}\right)-y^{*}\right]^{2}+a\left(r-r^{*}\right)^{2}+b\left[\left(\theta-r-\delta+m \delta+\varepsilon_{f}\right) \frac{K}{2 p m}\right]^{2} .
$$

The first-order condition is

$\frac{\partial L}{\partial r}=0=2 \beta\left[\alpha y^{*}+\beta\left(r-\hat{r}+\varepsilon_{y}\right)-y^{*}\right]+2 a\left(r-r^{*}\right)+2 b\left[\left(\theta-r-\delta+m \delta+\varepsilon_{f}\right) \frac{K}{2 p m}\right]\left(-\frac{K}{2 p m}\right)$,

which can be solved to obtain the central bank's best response, denoted $r^{c}$ :

$r^{c}=-\frac{1}{a+\beta^{2}+b\left(\frac{K}{2 p m}\right)^{2}}\left[\alpha \beta y^{*}-\beta^{2} \hat{r}+\beta^{2} \varepsilon_{y}-\beta y^{*}-a r^{*}-b\left(\frac{K}{2 p m}\right)^{2}\left(\theta+\varepsilon_{f}\right)+(1-m) \delta b\left(\frac{K}{2 p m}\right)^{2}\right]$

To compute the above expression, we require the interest rate expectations $\hat{r}$, to which we now turn. If expectations are on average correct in an equilibrium, then $\hat{r}=E\left[r^{c}\right]$, whence we can derive the following relation:

$$
\hat{r}=-\frac{1}{a+\beta^{2}+b\left(\frac{K}{2 p m}\right)^{2}}\left[\alpha \beta y^{*}-\beta^{2} \hat{r}-\beta y^{*}-a r^{*}-b\left(\frac{K}{2 p m}\right)^{2} \theta+(1-m) \delta b\left(\frac{K}{2 p m}\right)^{2}\right]
$$

This expression can be simplified to

$$
\hat{r}=-\frac{1}{a+b\left(\frac{K}{2 p m}\right)^{2}}\left[\alpha \beta y^{*}-\beta y^{*}-a r^{*}-b\left(\frac{K}{2 p m}\right)^{2} \theta+(1-m) \delta b\left(\frac{K}{2 p m}\right)^{2}\right]
$$

or, equivalently,

$$
\hat{r}=\frac{1}{a+b\left(\frac{K}{2 p m}\right)^{2}}\left[(1-\alpha) \beta y^{*}+a r^{*}+(\theta-\delta+m \delta)\left(\frac{K}{2 p m}\right)^{2} b\right] .
$$

By substituting the $\hat{r}$ term from (28) into (27) we obtain the equilibrium policy rate, namely, 


$$
\begin{aligned}
r^{c} & =-\frac{1}{a+\beta^{2}+b\left(\frac{K}{2 p m}\right)^{2}}\left\{\frac{\beta^{2}}{a+b\left(\frac{K}{2 p m}\right)^{2}}\left[\alpha \beta y^{*}-\beta y^{*}-a r^{*}-b\left(\frac{K}{2 p m}\right)^{2} \theta+(1-m) \delta b\left(\frac{K}{2 p m}\right)^{2}\right]+\beta^{2} \varepsilon_{y}\right\} \\
& -\frac{1}{a+\beta^{2}+b\left(\frac{K}{2 p m}\right)^{2}}\left[\alpha \beta y^{*}-\beta y^{*}-a r^{*}-b\left(\frac{K}{2 p m}\right)^{2}\left(\theta+\varepsilon_{f}\right)+(1-m) \delta b\left(\frac{K}{2 p m}\right)^{2}\right]
\end{aligned}
$$

Now we just simplify the above expression. First, note that upon collecting terms, it becomes

$$
\begin{gathered}
r^{c}=-\frac{1}{a+\beta^{2}+b\left(\frac{K}{2 p m}\right)^{2}}\left\{\frac{a+\beta^{2}+b\left(\frac{K}{2 p m}\right)^{2}}{a+b\left(\frac{K}{2 p m}\right)^{2}}\left[\alpha \beta y^{*}-\beta y^{*}-a r^{*}-b\left(\frac{K}{2 p m}\right)^{2} \theta+(1-m) \delta b\left(\frac{K}{2 p m}\right)^{2}\right]\right\} \\
-\frac{1}{a+\beta^{2}+b\left(\frac{K}{2 p m}\right)^{2}}\left\{\beta^{2} \varepsilon_{y}-b\left(\frac{K}{2 p m}\right)^{2} \varepsilon_{f}\right\} .
\end{gathered}
$$

Now define $A=a+\beta^{2}+b\left(\frac{K}{2 p m}\right)^{2}, B=a+b\left(\frac{K}{2 p m}\right)^{2}$, and $C=b\left(\frac{K}{2 p m}\right)^{2}$. Then the above expression implies

$$
r^{c}=\frac{1}{B}\left[-\alpha \beta y^{*}+\beta y^{*}+a r^{*}+b\left(\frac{K}{2 p m}\right)^{2} \theta-(1-m) \delta b\left(\frac{K}{2 p m}\right)^{2}\right]-\frac{1}{A}\left[\beta^{2} \varepsilon_{y}-b\left(\frac{K}{2 p m}\right)^{2} \varepsilon_{f}\right]
$$

or

$$
r^{c}=\frac{1}{B}\left[(1-\alpha) \beta y^{*}+a r^{*}+(\theta-\delta+m \delta) C\right]-\frac{1}{A}\left[\beta^{2} \varepsilon_{y}-C \varepsilon_{f}\right] .
$$

Similarly, we can simplify the expected interest rate $\hat{r}$ from equation (28) to be

$$
\hat{r}=\frac{1}{B}\left[(1-\alpha) \beta y^{*}+a r^{*}+(\theta-\delta+m \delta) C\right]-\frac{1}{A}\left(\beta^{2} \varepsilon_{y}-C \varepsilon_{f}\right)
$$

Thus $r^{c}$ and $\hat{r}$ have the following relation, $r^{c}=\hat{r}-\frac{1}{A}\left(\beta^{2} \varepsilon_{y}-C \varepsilon_{f}\right)$.

We also need to obtain the term for output $y$. From the Phillips curve relation (5), actual output is

$$
y=\alpha y^{*}+\beta\left(r^{c}-\hat{r}+\varepsilon_{y}\right)
$$


which upon substitution yields

$$
y=\alpha y^{*}+\frac{a+b\left(\frac{K}{2 p m}\right)^{2}}{a+\beta^{2}+b\left(\frac{K}{2 p m}\right)^{2}} \beta \varepsilon_{y}+\frac{b\left(\frac{K}{2 p m}\right)^{2}}{a+\beta^{2}+b\left(\frac{K}{2 p m}\right)^{2}} \beta \varepsilon_{f} .
$$

and finally,

$$
y=\alpha y^{*}+\frac{B}{A} \beta \varepsilon_{y}+\frac{C}{A} \beta \varepsilon_{f}=\alpha y^{*}+\frac{\beta}{A}\left(B \varepsilon_{y}+C \varepsilon_{f}\right) .
$$

\section{A.3 Derivation of Expected Welfare Loss $E\left[L^{n}\right]$ in Section 3.1.}

To compute this moment, we first calculate the welfare loss expression $L^{n}$, by substituting (29) and (31) into the objective (7):

$$
\begin{aligned}
L= & {\left[\alpha y^{*}+\frac{B}{A} \beta \varepsilon_{y}+\frac{C}{A} \beta \varepsilon_{f}-y^{*}\right]^{2} } \\
& +a\left[\frac{1}{B}\left[(1-\alpha) \beta y^{*}+a r^{*}+(\theta-\delta+m \delta) C\right]-\frac{1}{A}\left(\beta^{2} \varepsilon_{y}-C \varepsilon_{f}\right)-r^{*}\right]^{2} \\
& +b\left[\left(\theta-\left(\frac{1}{B}\left[(1-\alpha) \beta y^{*}+a r^{*}+(\theta-\delta+m \delta) C\right]-\frac{1}{A}\left(\beta^{2} \varepsilon_{y}-C \varepsilon_{f}\right)\right)-\delta+m \delta+\varepsilon_{f}\right) \frac{K}{2 p m}\right]^{2} \\
= & {\left[(\alpha-1) y^{*}+\frac{B}{A} \beta \varepsilon_{y}+\frac{C}{A} \beta \varepsilon_{f}\right]^{2}+a\left[\frac{(1-\alpha) \beta y^{*}+(a-B) r^{*}+(\theta-\delta+m \delta) C}{B}-\frac{\beta^{2} \varepsilon_{y}-C \varepsilon_{f}}{A}\right]^{2} } \\
& +b\left[\left(\frac{B(\theta-\delta+m \delta)-\left[(1-\alpha) \beta y^{*}+a r^{*}+(\theta-\delta+m \delta) C\right]}{B}+\frac{\beta^{2} \varepsilon_{y}+(A-C) \varepsilon_{f}}{A}\right) \frac{K}{2 p m}\right]^{2} .
\end{aligned}
$$

To simplify, note that $(a-B) r^{*}=-C r^{*}$, in the third line; and $(B-C)(\theta-\delta+m \delta)=a(\theta-\delta+m \delta)$, and $(A-C) \varepsilon_{f}=\left(a+\beta^{2}\right) \varepsilon_{f}$, for the fourth line. Thus we can rewrite the above expression as

$$
\begin{aligned}
L= & {\left[(\alpha-1) y^{*}+\frac{B}{A} \beta \varepsilon_{y}+\frac{C}{A} \beta \varepsilon_{f}\right]^{2}+a\left[\frac{(1-\alpha) \beta y^{*}+\left(\theta-\delta+m \delta-r^{*}\right) C}{B}-\frac{\beta^{2} \varepsilon_{y}-C \varepsilon_{f}}{A}\right]^{2} } \\
& +b\left(\frac{K}{2 p m}\right)^{2}\left[\left(\frac{-(1-\alpha) \beta y^{*}-a r^{*}+(\theta-\delta+m \delta) a}{B}+\frac{\beta^{2} \varepsilon_{y}+\left(a+\beta^{2}\right) \varepsilon_{f}}{A}\right)\right]^{2} \\
= & {\left[(\alpha-1) y^{*}+\frac{B}{A} \beta \varepsilon_{y}+\frac{C}{A} \beta \varepsilon_{f}\right]^{2}+a\left[\frac{(1-\alpha) \beta y^{*}+\left(\theta-\delta+m \delta-r^{*}\right) C}{B}-\frac{\beta^{2} \varepsilon_{y}-C \varepsilon_{f}}{A}\right]^{2} } \\
& +C\left[\left(-\frac{(1-\alpha) \beta y^{*}+a r^{*}-(\theta-\delta+m \delta) a}{B}+\frac{\beta^{2} \varepsilon_{y}+\left(a+\beta^{2}\right) \varepsilon_{f}}{A}\right)\right]^{2} .
\end{aligned}
$$


Now that we have the expression for welfare loss $L$, we can compute its moments, which rely on joint stochastic properties of the real and financial shocks $\varepsilon_{y}$ and $\varepsilon_{f}$. Recall that the distribution of the shocks is the following. $\varepsilon \equiv\left[\varepsilon_{y}, \varepsilon_{f}\right]^{\prime}$, then $\varepsilon \sim[0, V]$, where the covariance matrix $V$ is of the form $V=\left[\begin{array}{cc}\sigma_{y}^{2} & \rho_{y, f} \\ \rho_{y, f} & \sigma_{f}^{2}\end{array}\right]$.

Then we can take expectations of (32). In the following, we first express the constant terms, then the stochastic ones, i.e. those that depend on the moments of $\varepsilon_{y}$ and $\varepsilon_{f}$. Specifically,

$$
\begin{aligned}
E[L]= & (\alpha-1)^{2} y^{* 2}+a\left[\frac{(1-\alpha) \beta y^{*}+\left(\theta-\delta+m \delta-r^{*}\right) C}{B}\right]^{2} \\
& +C\left[\frac{(1-\alpha) \beta y^{*}+a r^{*}-(\theta-\delta+m \delta) a}{B}\right]^{2} \\
& +\left(\left[\frac{B}{A}\right]^{2} \beta^{2}+a\left[\frac{\beta^{2}}{A}\right]^{2}+C\left[\frac{\beta^{2}}{A}\right]^{2}\right) \sigma_{y}^{2}+\left(\left[\frac{C}{A}\right]^{2} \beta^{2}+a\left[\frac{C}{A}\right]^{2}+C\left[\frac{\left(a+\beta^{2}\right)}{A}\right]^{2}\right) \sigma_{f}^{2} \\
& +2\left(\frac{B}{A} \frac{C}{A} \beta^{2}-a \frac{\beta^{2}}{A} \frac{C}{A}+C \frac{\beta^{2}}{A} \frac{\left(a+\beta^{2}\right)}{A}\right) \rho_{y, f} \\
= & (\alpha-1)^{2} y^{* 2}+a\left[\frac{(1-\alpha) \beta y^{*}+\left(\theta-\delta+m \delta-r^{*}\right) C}{B}\right]^{2} \\
& +C\left[\frac{(1-\alpha) \beta y^{*}+a r^{*}-(\theta-\delta+m \delta) a}{B}\right]^{2} \\
& +\frac{B^{2}+a \beta^{2}+C \beta^{2}}{A^{2}} \beta^{2} \sigma_{y}^{2}+\frac{C^{2}\left(\beta^{2}+a\right)+C\left(a+\beta^{2}\right)^{2}}{A^{2}} \sigma_{f}^{2}+2 C \beta^{2} \frac{B-a+a+\beta^{2}}{A^{2}} \rho_{y, f},
\end{aligned}
$$

or

$$
\begin{aligned}
E\left[L^{n}\right]= & (\alpha-1)^{2} y^{* 2}+a\left[\frac{(1-\alpha) \beta y^{*}+\left(\theta-\delta+m \delta-r^{*}\right) C}{B}\right]^{2} \\
& +C\left[\frac{(1-\alpha) \beta y^{*}+a r^{*}-(\theta-\delta+m \delta) a}{B}\right]^{2} \\
& +\frac{B^{2}+\beta^{2}(a+C)}{A^{2}} \beta^{2} \sigma_{y}^{2}+\frac{\left(a+\beta^{2}\right)^{2}\left(C^{2}+C\right)}{A^{2}} \sigma_{f}^{2}+2 C \beta^{2} \frac{B+\beta^{2}}{A^{2}} \rho_{y, f}
\end{aligned}
$$

In contrast, the cooperative solution features two conditions: $\hat{r}=r^{c}=r^{*}$; and $r^{*}=\theta-(1-$ $m) \delta$. Substituting these conditions into the objective function (7) and taking expectations yields the expected loss under perfect anchoring, $E\left[L^{c}\right]$ :

$$
\begin{aligned}
E\left[L^{c}\right] & =E\left[\left[(\alpha-1) y^{*}+\beta \varepsilon_{y}\right]^{2}+\left(\frac{K}{2 p m} \varepsilon_{f}\right)^{2}\right] \\
& =(\alpha-1)^{2} y^{* 2}+\beta^{2} \sigma_{y}^{2}+\frac{C}{b} \sigma_{f}^{2},
\end{aligned}
$$


where the second line uses the fact that $C=b\left(\frac{K}{2 p m}\right)^{2}$. The difference in expected loss $\Delta=$ $E[L]-E\left[L^{c}\right]$ is calculated from (33) and (34) to be

$$
\begin{aligned}
\Delta= & a\left[\frac{(1-\alpha) \beta y^{*}+\left(\theta-\delta+m \delta-r^{*}\right) C}{B}\right]^{2}+C\left[\frac{(1-\alpha) \beta y^{*}+a r^{*}-(\theta-\delta+m \delta) a}{B}\right]^{2} \\
& +\frac{B^{2}+\beta^{2}(a+C)-A^{2}}{A^{2}} \beta^{2} \sigma_{y}^{2}+\frac{b\left(a+\beta^{2}\right)^{2}\left(C^{2}+C\right)-A^{2} C}{b A^{2}} \sigma_{f}^{2}+2 C \beta^{2} \frac{B+\beta^{2}}{A^{2}} \rho_{y}(\mathcal{\jmath} 5)
\end{aligned}
$$

Proposition 3: In a dual tradeoff model, the central bank's expected loss increases monotonically with the dependence between financial and real shocks.

Proof: We have to show that $\Delta=E[L]-E\left[L^{c}\right]$ increases with dependence. Dependence is measured by $\rho_{y, f}$, and the expected loss differential is presented in equation (35). From examination of the last term, it is evident that the coefficient on $\rho_{y, f}$ is unambiguously positive. Therefore $E[L]-E\left[L^{c}\right]$ increases with $\rho_{y, f}$, as was to be shown.

Proposition 4: Inefficiency of Bank Equilibrium Investment. Part A: In market equilibrium, the bank's investment is larger than the planner's solution, i.e., $I^{E}>I^{p}$. Moreover, $\sqrt{3} I^{p}<I^{E}<2 I^{p}$. Part B: In market equilibrium, liquidity risk provides some market discipline, but investment is still excessive.

Proof of Part A: Subtracting (13) from (12), one can get

$$
\gamma \omega\left(3\left(I^{p}\right)^{2}-\left(I^{E}\right)^{2}\right)+\left(2 I^{p}-I^{E}\right)\left(\omega \hat{r} K-\gamma r_{1}-\gamma \delta+\gamma m \delta\right) \equiv 0 .
$$

The banks borrow short-term debt only if long-term debt is too costly, or $\omega<\omega I^{p} \leq r_{1}+\delta$. Therefore

$$
\omega \hat{r} K-\gamma\left(r_{1}+\delta\right)+\gamma m \delta \geq \omega(\hat{r} K-\gamma)+\gamma m \delta>0
$$

as long as $\hat{r} K-\gamma>0$. This latter condition is fairly weak: since $\hat{r}>1>\gamma$, the inequality strictly holds if $I^{p}>K>1$.

Suppose that $I^{E}<I^{E}$, then $\gamma \omega\left(3\left(I^{p}\right)^{2}-\left(I^{E}\right)^{2}\right)+\left(2 I^{p}-I^{E}\right)\left(\omega \hat{r} K-\gamma r_{1}-\gamma \delta+\gamma m \delta\right)>0$. A contradiction.

Suppose that $I^{p} \leq I^{E} \leq \sqrt{3} I^{p}$, then $\gamma \omega\left(3\left(I^{p}\right)^{2}-\left(I^{E}\right)^{2}\right)+\left(2 I^{p}-I^{i}\right)\left(\omega \hat{r} K-\gamma r_{1}-\gamma \delta+\gamma m \delta\right)>$ 0 . A contradiction.

Suppose that $I^{E} \geq 2 I^{p}$, then $\gamma \omega\left(3\left(I^{p}\right)^{2}-\left(I^{E}\right)^{2}\right)+\left(2 I^{p}-I^{i}\right)\left(\omega \hat{r} K-\gamma r_{1}-\gamma \delta+\gamma m \delta\right)<0$. A contradiction.

Therefore, $\sqrt{3} I^{p}<I^{E}<2 I^{p}$. 
Part $B$. This part of the proof involves evaluating comparative statics of the liquidity effect. Using the implicit function theorem, we can take the derivative of (17) with respect to $m$ to get

$$
\frac{\partial I^{E}}{\partial m}=-\frac{K \delta+\gamma I \delta}{\omega K-\gamma r_{1}-\gamma \delta+\gamma m \delta+2 I^{E} \gamma \omega} .
$$

The denominator can be rewritten as

$$
\omega K+\gamma\left(\omega I^{E}-r_{1}\right)+\gamma\left(\omega I^{E}-\delta\right)+\gamma m \delta .
$$

Since $\omega I^{E}$ is the return on investment, $\omega I^{E}>r_{1}>\delta$ by assumption. Therefore the denominator is positive, and $\frac{\partial I^{E}}{\partial m}<0$.

\section{A.4 Derivation of Optimal Short Rate $r^{E}$ in Model of Section 4.2}

Recall that the central bank's program is

$$
\min _{r^{E}} L_{C}=\left(y-y^{*}\right)^{2}+a\left(r^{E}-r^{*}\right)^{2}+b \gamma \sum_{i} I^{i} G\left(\varepsilon_{y}^{i *}\right)(i)
$$

For simplicity, we have assumed that bankruptcy formally occurs in the end of the period, $t_{2}$. Thus, the share of bankrupted banks can be written as

$$
\frac{m I^{E} \hat{r} r^{E}+(1-m) I^{E}\left(r_{1}+\delta\right)-\omega\left[I^{E}+\beta\left(r^{E}-\hat{r}+\varepsilon_{y}\right)\right] I^{E}}{K} .
$$

The central bank's decision problem can now be rewritten as

$$
\begin{aligned}
\min _{r^{E}} L_{C}= & {\left[\left(I^{E}-I^{*}\right)+\beta\left(r^{E}-\hat{r}+\varepsilon_{y}\right)\right]^{2}+a\left(r^{E}-r^{*}\right)^{2} } \\
& +b \gamma I^{E} \frac{m I^{E} \hat{r} r^{E}+(1-m) I^{E}\left(r_{1}+\delta\right)-\omega\left[I^{E}+\beta\left(r^{E}-\hat{r}+\varepsilon_{y}\right)\right] I^{E}}{K}
\end{aligned}
$$

The first order condition is linear in $r^{E}$ so that we can solve $\hat{r}$ by taking expectations. The first order condition yields

$$
\frac{\partial L_{C}}{\partial r^{E}}=2 \beta\left[\left(I^{E}-I^{*}\right)+\beta\left(r^{E}-\hat{r}+\varepsilon_{y}\right)\right]+2 a\left(r^{E}-r^{*}\right)+\frac{b \gamma I^{E}}{K}\left(m I^{E} \hat{r}-\omega I^{E} \beta\right)=0 .
$$

Since in a rational expectations equilibrium $E\left[r^{E}\right]=\hat{r}$, we take expectations on the first order condition, in order to obtain 


$$
2 \beta\left(I^{E}-I^{*}\right)+2 a\left(\hat{r}-r^{*}\right)+\frac{b \gamma I^{E}}{K}\left(m I^{E} \hat{r}-\omega I^{E} \beta\right)=0,
$$

which implies that interest rate expectations satisfy

$$
\hat{r}=\frac{2 a K r^{*}-2 \beta K\left(I^{E}-I^{*}\right)+b \gamma\left(I^{E}\right)^{2} \omega \beta}{2 a K+b \gamma\left(I^{E}\right)^{2} m} .
$$

We now insert $\hat{r}$ into the first order condition, and solve for the central bank's optimal short rate to obtain $r^{E}=\frac{2 a K r^{*}-2 \beta K\left(I^{E}-I^{*}\right)+b \gamma\left(I^{E}\right)^{2} \omega \beta}{2 a K-b \gamma\left(I^{E}\right)^{2} m}-\frac{\beta^{2}}{a+\beta^{2}} \varepsilon_{y}$,

or, equivalently,

$$
r^{E}=\frac{2 a K}{2 a K+b \gamma\left(I^{E}\right)^{2} m} r^{*}-\frac{2 \beta K\left(I^{E}-I^{*}\right)}{2 a K+b \gamma\left(I^{E}\right)^{2} m}+\frac{b \gamma\left(I^{E}\right)^{2} \omega \beta}{2 a K+b \gamma\left(I^{E}\right)^{2} m}-\frac{\beta^{2}}{a+\beta^{2}} \varepsilon_{y},
$$

which is presented as equation (14) of the text.

\section{Proof of the Impossibility Result, Proposition 5}

We have to show that when the central bank's rates are equal, $r^{E}=r^{O}$, then the target rate is a linear function of the investment gap: $r^{*}=\frac{\beta}{a}\left(I^{E}-I^{*}\right)+\frac{\omega \beta}{m}$.

The central bank can use the same rate to control both inflation and targeting only if $r^{E}-r^{O}$ is identically zero. We solve this condition by taking the difference $r^{E}-r^{0}$ :

$$
\begin{aligned}
r^{E}-r^{0}= & \frac{2 a K}{2 a K+b \gamma\left(I^{E}\right)^{2} m} r^{*}-\frac{2 \beta K\left(I^{E}-I^{*}\right)}{2 a K+b \gamma\left(I^{E}\right)^{2} m}+\frac{b \gamma\left(I^{E}\right)^{2} \omega \beta}{2 a K+b \gamma\left(I^{E}\right)^{2} m}-\frac{\beta^{2}}{a+\beta^{2}} \varepsilon_{y} \\
& -\left[r^{*}-\frac{\beta}{a}\left(I^{E}-I^{*}\right)-\frac{\beta^{2}}{a+\beta^{2}} \varepsilon_{y}\right] \\
= & {\left[\frac{2 a K}{2 a K+b \gamma\left(I^{E}\right)^{2} m}-1\right] r^{*}+\beta\left[I^{E}-I^{*}\right]\left[\frac{1}{a}-\frac{2 K}{2 a K+b \gamma\left(I^{E}\right)^{2} m}\right]+\frac{b \gamma\left(I^{E}\right)^{2} \omega \beta}{2 a K+b \gamma\left(I^{E}\right)^{2} m} } \\
= & {\left[\frac{2 a K-2 a K-b \gamma\left(I^{E}\right)^{2} m}{2 a K+b \gamma\left(I^{E}\right)^{2} m}\right] r^{*}+\beta\left[I^{E}-I^{*}\right]\left[\frac{2 a K+b \gamma\left(I^{E}\right)^{2} m-2 a K}{a\left[2 a K+b \gamma\left(I^{E}\right)^{2} m\right]}\right] \frac{b \gamma\left(I^{E}\right)^{2} \omega \beta}{2 a K+b \gamma\left(I^{E}\right)^{2} m} } \\
= & {\left[\frac{-b \gamma\left(I^{E}\right)^{2} m}{2 a K+b \gamma\left(I^{E}\right)^{2} m}\right] r^{*}+\beta\left[I^{E}-I^{*}\right]\left[\frac{b \gamma\left(I^{E}\right)^{2} m}{a\left[2 a K+b \gamma\left(I^{E}\right)^{2} m\right]}\right]+\frac{b \gamma\left(I^{E}\right)^{2} \omega \beta}{2 a K+b \gamma\left(I^{E}\right)^{2} m} } \\
= & {\left[\frac{-b \gamma\left(I^{E}\right)^{2} m}{2 a K+b \gamma\left(I^{E}\right)^{2} m}\right] r^{*}+\left[\frac{b \beta \gamma\left(I^{E}\right)^{2} m}{a\left[2 a K+b \gamma\left(I^{E}\right)^{2} m\right]}\right]\left(I^{E}-I^{*}\right)+\frac{b \gamma\left(I^{E}\right)^{2} \omega \beta}{2 a K+b \gamma\left(I^{E}\right)^{2} m}, }
\end{aligned}
$$

or

$$
r^{E}-r^{0}=\left[\frac{b \gamma\left(I^{E}\right)^{2}}{2 a K+b \gamma\left(I^{E}\right)^{2} m}\right]\left[m\left(\frac{\beta}{a}\left(I^{E}-I^{*}\right)-r^{*}\right)+\omega \beta\right] .
$$


The central bank can use the same rate to control both inflation and targeting only if the expression in (37) is identically zero, i.e. at least one of the terms on the RHS is zero. Let us examine the first term. This term is non-zero because the central bank cares about fragility $(b>0)$, fire sales occur $(\gamma>0)$, investment is positive $\left(I^{E}>0\right)$, and there is always some short term debt in the economy $(m>0)$. Therefore it suffices to examine only the second term. This second term is zero if the target rate is a specific linear function the investment gap: $r^{*}=\frac{\beta}{a}\left(I^{E}-I^{*}\right)+\frac{\omega \beta}{m}$, as was to be shown.

\section{B Calibrations for Optimal Investment, Short Rates, and Threshold Discount Rate}

We calibrate the key variables from Section 4, in order to illustrate them graphically.

\section{B.1 Calibration of Investment and Short Rates}

In this part we calibrate variables from Section 4.2 and 4.3. Aggregate investment is represented in equations (12) and (13), while short rates under fragility and traditional central banking are in equations (15) and (14). The main parameters are described below.

Table 2: Description of Variables in Investment and Short Rates

\begin{tabular}{l|l}
\hline Parameter & Interpretation \\
\hline $1 . a$ & Cost to central bank of missing inflation or interest target \\
\hline $2 . b$ & Cost to central bank of missing investment target \\
\hline $3 . \beta$ & Phillips curve-based cost to central bank of missing interest target \\
\hline $4 . r^{*}$ & Target interest rate \\
\hline $5 . I^{E}-I^{*}$ & Gap between optimal and target investment \\
\hline $6 . I^{*}$ & Optimal Investment \\
\hline $7 . K$ & Total equity in banking system \\
\hline $8 \cdot \gamma$ & Multiplier for systemic costs relative to $I$, which measures fire-sale costs \\
\hline $9 \cdot m$ & Fraction of short-term debt in banking system, which measures system illiquidity \\
\hline $10 \cdot \varepsilon_{y}$ & Output shock \\
\hline
\end{tabular}

We approach determination of the parameter values through a combination of natural constraints, theoretical considerations, and banking practice. Notice that:

- Typical inflation targeting central banks put much higher weight on inflation loss than output loss, i.e., $a>>1$; 
- The ratio $\frac{I^{E}}{k}$ reflects the bank's leverage ratio. The typical leverage in the banking industry is about 12.5 , rarely below 5 ; therefore, $\frac{I^{E}}{K}=5$ (the lowest banking leverage) may be a good guess;

- The value $\gamma \Sigma_{i} I^{i}$ is the fire sale loss of one unit liquidated asset, therefore $\gamma I^{E}<1-$ even in the worse case when all the bank assets are liquidated, the banks can still recover some value $\left(1-\gamma I^{E}\right.$ per unit);

- The reliance on short-term debt varies quite a lot across banks, and depends mainly on how much investment banking business one bank gets involved. However, post-crisis banks tend to focus more on the mainstream banking, and $m$ is mostly between $20 \%$ and $40 \%$ in Europe and US;

- For regularity, we require $2 a K-b \gamma\left(I^{E}\right)^{2} m>0$.

\section{B.2 Calibrating the Threshold Discount Rate}

We now calibrate the threshold discount rate $d$ for the infinitely repeated game from Section 4.4. The discount rate is given by expression (21), reproduced here:

$$
d \geq \frac{\tilde{L}_{C}^{p}-L_{C}^{p}}{\tilde{L}_{C}^{p}-L_{C}^{E}} \equiv \bar{d} .
$$

The expressions for $\tilde{L}_{C}^{p}, L_{C}^{p}$ and $L_{C}^{E}$ depend on similar parameters to those for the optimal policy rates in section 1 above. In particular, equation (21) gives the central bank's loss function as

$$
\begin{aligned}
L_{C}\left(r^{c}, \hat{r}, I^{i}\right)= & {\left[\left(I^{i}-I^{*}\right)+\beta\left(r^{c}-\hat{r}+\varepsilon_{y}\right)\right]^{2}+a\left(r^{c}-r^{*}\right)^{2} } \\
& +b \gamma I^{i} \frac{m I^{i} \hat{r} r^{c}+(1-m) I^{i}\left(r_{1}+\delta\right)-\omega\left[I^{i}+\beta\left(r^{c}-\hat{r}+\varepsilon_{y}\right)\right] I^{i}}{K},
\end{aligned}
$$

where $r^{c} \in\left\{r^{E}, r^{p}\right\}$ and $I^{i} \in\left\{I^{E}, I^{p}\right\}$.

Preliminary results for Computing threshold.

Before we compute the threshold $\bar{d}$, recall that $r^{E}$ and $r^{p}$ are calculated from equation (23) in the text, as

$$
r^{p}=\frac{2 a K}{2 a K+b \gamma\left(I^{p}\right)^{2} m} r^{*}-\frac{2 \beta K\left(I^{p}-I^{*}\right)}{2 a K+b \gamma\left(I^{p}\right)^{2} m}+\frac{b \gamma\left(I^{p}\right)^{2} \omega \beta}{2 a K+b \gamma\left(I^{p}\right)^{2} m}-\frac{\beta^{2}}{a+\beta^{2}} \varepsilon_{y}
$$

and

$$
r^{E}=\frac{2 a K}{2 a K+b \gamma\left(I^{E}\right)^{2} m} r^{*}-\frac{2 \beta K\left(I^{E}-I^{*}\right)}{2 a K+b \gamma\left(I^{E}\right)^{2} m}+\frac{b \gamma\left(I^{E}\right)^{2} \omega \beta}{2 a K+b \gamma\left(I^{E}\right)^{2} m}-\frac{\beta^{2}}{a+\beta^{2}} \varepsilon_{y} .
$$

Further, $I^{E}$ and $I^{p}$ satisfy the following conditions from equations (17) and (18) in the text:

$$
\omega I^{E} K-r_{1} K-K \delta+K m \delta-\gamma I^{E} r_{1}-\gamma I^{E} \delta+\gamma I^{E} m \delta+\gamma\left(I^{E}\right)^{2} \omega=0,
$$


and

$$
2 \omega I^{p} K-r_{1} K-K \delta+K m \delta-2 \gamma I^{p} r_{1}-2 \gamma I^{p} \delta+2 \gamma I^{p} m \delta-3 \gamma\left(I^{p}\right)^{2} \omega=0,
$$

respectively.

Computing the threshold $\bar{d}$.

Now we can compute the three different elements of the threshold discount rate in (38)-namely $L_{C}^{p}$, $L_{C}^{E}$, and $\tilde{L}_{C}^{p}$. The first two are straightforward since they involve the bank and central bank both playing cooperate or deviate:

$$
\begin{aligned}
L_{C}^{p}\left(r^{p}, \hat{r}, I^{p}\right)= & {\left[\left(I^{p}-I^{*}\right)+\beta\left(r^{p}-\hat{r}+\varepsilon_{y}\right)\right]^{2}+a\left(r^{p}-r^{*}\right)^{2} } \\
& +b \gamma I^{p} \frac{m I^{p} \hat{r} r^{p}+(1-m) I^{p}\left(r_{1}+\delta\right)-\omega\left[I^{p}+\beta\left(r^{p}-\hat{r}+\varepsilon_{y}\right)\right] I^{p}}{K} ;
\end{aligned}
$$

and

$$
\begin{aligned}
L_{C}^{E}\left(r^{E}, \hat{r}, I^{E}\right)= & {\left[\left(I^{E}-I^{*}\right)+\beta\left(r^{E}-\hat{r}+\varepsilon_{y}\right)\right]^{2}+a\left(r^{E}-r^{*}\right)^{2} } \\
& +b \gamma I^{E} \frac{m I^{E} \hat{r} r^{E}+(1-m) I^{E}\left(r_{1}+\delta\right)-\omega\left[I^{E}+\beta\left(r^{E}-\hat{r}+\varepsilon_{y}\right)\right] I^{E}}{K}(\text { (40) }
\end{aligned}
$$

The third payoff, $\tilde{L}_{C}^{p}$, is different because it reflects the central bank's payoff (by choosing $r=r^{p}$ ) if the bank deviates $\left(I=I^{E}\right)$ for one period:

$$
\begin{aligned}
\tilde{L}_{C}^{p}\left(r^{p}, \hat{r}, I^{E}\right)= & {\left[\left(I^{E}-I^{*}\right)+\beta\left(r^{p}-\hat{r}+\varepsilon_{y}\right)\right]^{2}+a\left(r^{p}-r^{*}\right)^{2} } \\
& +b \gamma I^{E} \frac{m I^{E} \hat{r} r^{p}+(1-m) I^{E}\left(r_{1}+\delta\right)-\omega\left[I^{E}+\beta\left(r^{p}-\hat{r}+\varepsilon_{y}\right)\right] I^{E}}{K} .
\end{aligned}
$$

Thus the threshold discount factor $\bar{d}$ in (38) can be computed from equations (39) to (41), and the short rate and investment expressions from Section 2.1. 


\section{Figure 2: Threshold Discount Rate for Infinite-Horizon Game}

The figure shows the threshold discount rate $d$ from equation (21). The calibration is as in Appendix B. The parameters $a$ and $b$ denote the central bank's weight on inflation and fragility, respectively.

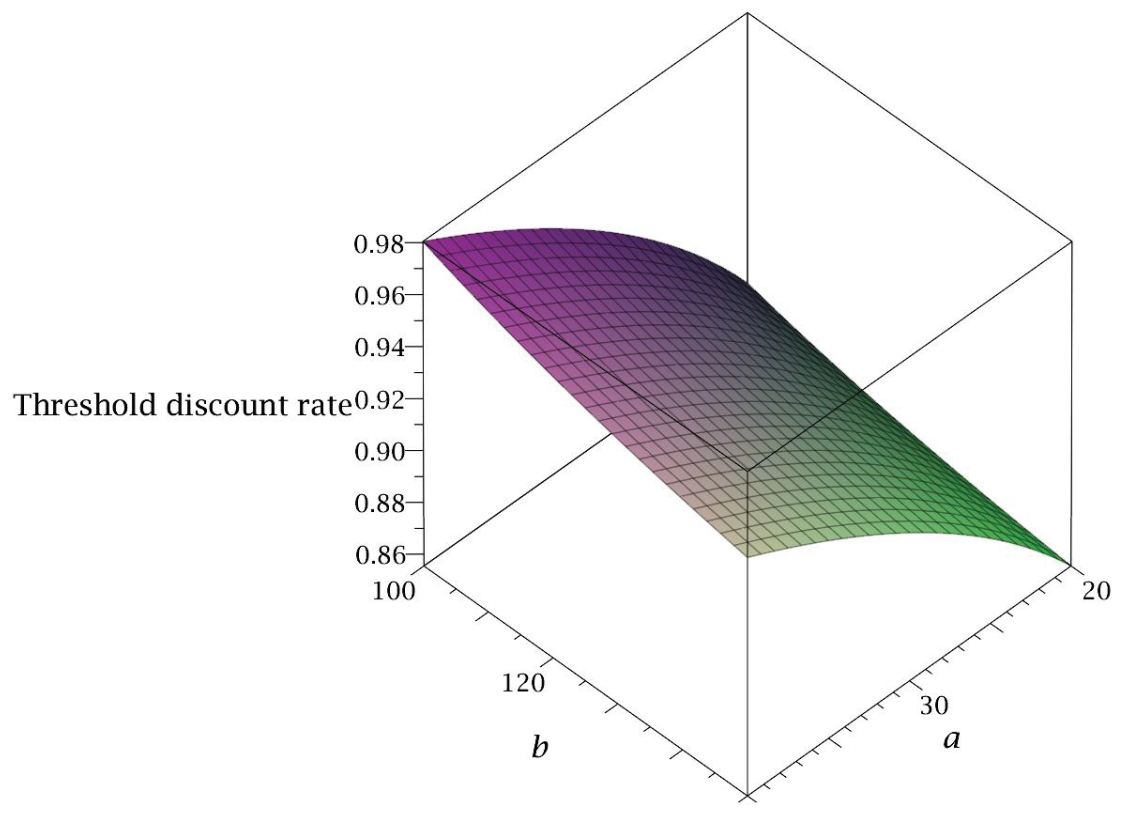




\section{Figure 3: Aggregate Investment with Fragility-Conscious Central Bank}

The figure shows the average investment surface from equations (12) and (13). The calibration is as in Appendix B. The parameters $a$ and $b$ denote the central bank's weight on inflation and fragility, respectively. The blue surfaces correspond to equation (13), and show the optimal investment when the central bank targets both inflation and fragility- the light blue corresponds to $m=0.4$ while the dark blue corresponds to $m=0.6$. The yellow surface corresponds to equation (12), and shows the optimal investment when the central bank only targets inflation.

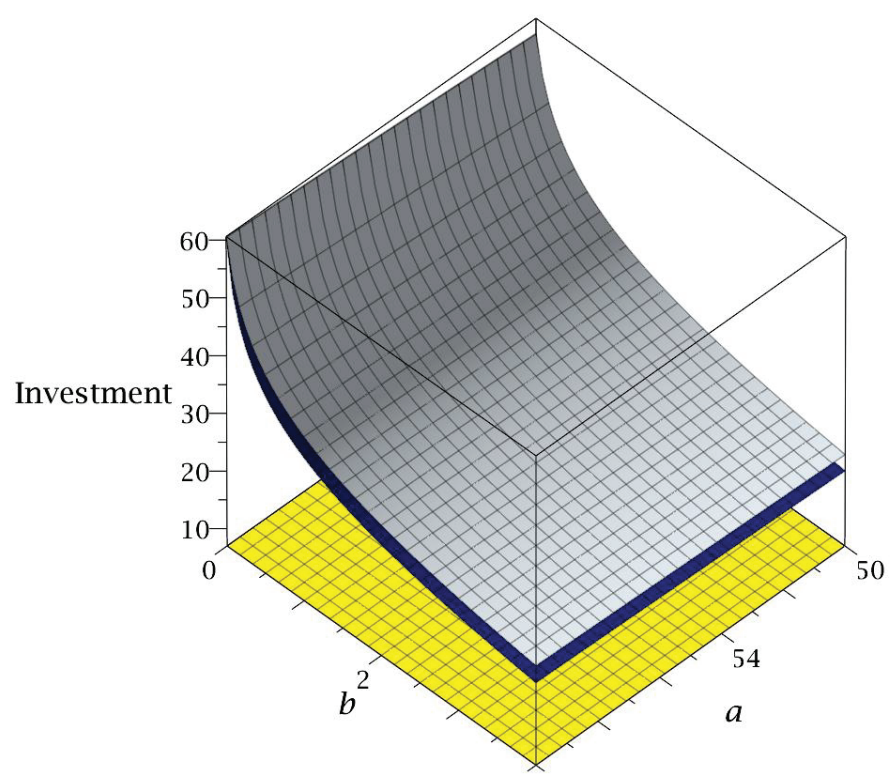


Figure 4: Optimal Policy Rates under Traditional Targeting and Fragility Concerns

The figure shows the optimal policy rates $r^{0}$ and $r^{E}$ from equations (15) and (14). The calibration is as in Appendix B. The parameters $a$ and $b$ denote the central bank's weight on inflation and fragility, respectively. The blue surfaces correspond to equation (14), and depict the optimal policy rate when the central bank targets both inflation and fragility- the light blue corresponds to $m=0.4$, while the dark blue corresponds to $m=0.6$. The yellow surface corresponds to equation (15), and shows the optimal short rate when the central bank only targets inflation.

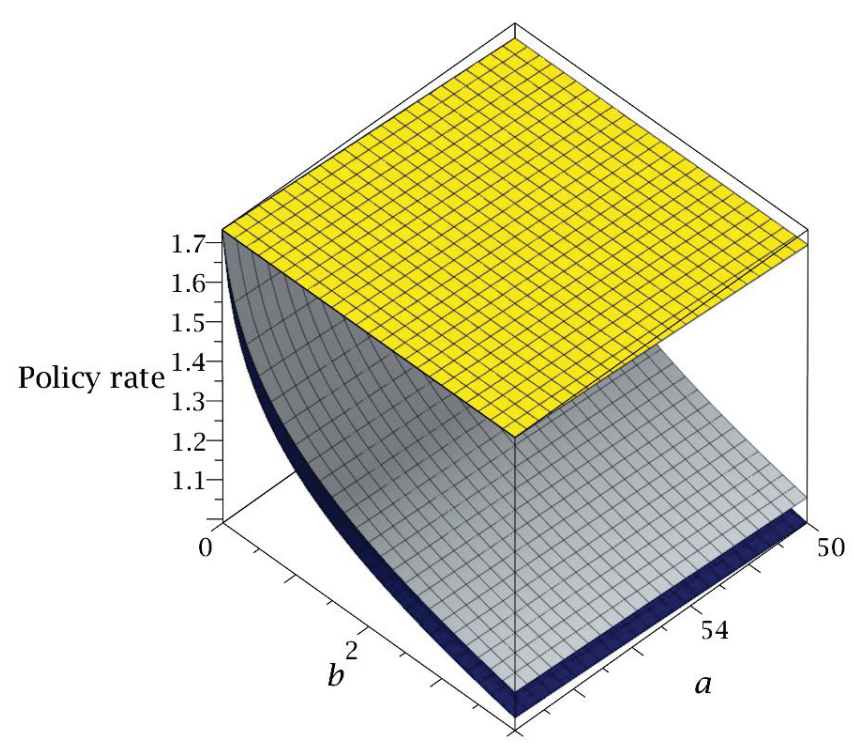

